OPEN ACCESS

Edited by:

Jose Solla-Gullon,

University of Alicante, Spain

Reviewed by:

Rosa Aran Ais,

Fritz-Haber-Institut, Germany

Qingying Jia,

Northeastern University, United States

${ }^{*}$ Correspondence:

Manoj Neergat

nmanoj@iitb.ac.in

Specialty section:

This article was submitted to

Electrochemistry,

a section of the journal

Frontiers in Chemistry

Received: 13 June 2019 Accepted: 10 September 2019

Published: 04 October 2019

Citation:

Devivaraprasad R, Nalajala N, Bera B and Neergat $M$ (2019) Electrocatalysis

of Oxygen Reduction Reaction on

Shape-Controlled Pt and Pd

Nanoparticles-Importance of Surface

Cleanliness and Reconstruction.

Front. Chem. 7:648

doi: 10.3389/fchem.2019.00648

\section{Electrocatalysis of Oxygen Reduction Reaction on Shape-Controlled Pt and Pd Nanoparticles - Importance of Surface Cleanliness and Reconstruction}

\author{
Ruttala Devivaraprasad ${ }^{1}$, Naresh Nalajala ${ }^{2}$, Bapi Bera ${ }^{1}$ and Manoj Neergat ${ }^{1 *}$ \\ ${ }^{1}$ Department of Energy Science and Engineering, Indian Institute of Technology Bombay, Mumbai, India, ${ }^{2}$ National Chemical \\ Laboratory, Catalysis Division, Pune, India
}

Shape-controlled precious metal nanoparticles have attracted significant research interest in the recent past due to their fundamental and scientific importance. Because of their crystallographic-orientation-dependent properties, these metal nanoparticles have tremendous implications in electrocatalysis. This review aims to discuss the strategies for synthesis of shape-controlled platinum $(\mathrm{Pt})$ and palladium $(\mathrm{Pd})$ nanoparticles and procedures for the surfactant removal, without compromising their surface structural integrity. In particular, the electrocatalysis of oxygen reduction reaction (ORR) on shape-controlled nanoparticles ( $\mathrm{Pt}$ and $\mathrm{Pd}$ ) is discussed and the results are analyzed in the context of that reported with single crystal electrodes. Accepted theories on the stability of precious metal nanoparticle surfaces under electrochemical conditions are revisited. Dissolution, reconstruction, and comprehensive views on the factors that contribute to the loss of electrochemically active surface area (ESA) of nanoparticles leading to an inevitable decrease in ORR activity are presented. The contribution of adsorbed electrolyte anions, in-situ generated adsorbates and contaminants toward the ESA reduction are also discussed. Methods for the revival of activity of surfaces contaminated with adsorbed impurities without perturbing the surface structure and its implications to electrocatalysis are reviewed.

Keywords: adsorption, dissolution, oxygen reduction reaction, platinum, palladium, reconstruction, shape-control, surface cleaning

\section{INTRODUCTION}

Fuel cell, an electrochemical device, converts chemical energy to electrical energy. In low temperature polymer electrolyte membrane fuel cell (PEMFC), the electrodes are generally based on carbon-supported platinum (Pt) nanoparticles. In a cell, protons produced at the anode from the fuel oxidation reaction are transported through the electrolyte membrane (usually, Nafion ${ }^{\circledR}-\mathrm{a}$ sulphonated tetrafluorethylene copolymer) to the cathode, wherein oxygen reduction reaction (ORR) takes place. The two reactions set up a potential difference between the electrodes and it drives the electrons through the external circuit. However, Pt-based precious metal catalysts are prohibitively expensive for the widespread use of PEMFCs. Therefore, it is imperative to reduce 
either the Pt content and improve its catalytic activity or to replace it completely with cheaper alternatives at the cathode in fuel cells.

$\mathrm{Pd}$ is considered to be a promising alternative to $\mathrm{Pt}$, perhaps because of their similar crystal structure (face centered cubic) and electronic configuration (d-transition metals) (Mittermeier et al., 2017). Most importantly, Pd is situated at the peak of the volcano plot of ORR activity, adjacent to Pt (Nørskov et al., 2004). Though, the electrochemical stability of $\mathrm{Pd}$ in acidic conditions is relatively poor as compared to $\mathrm{Pt}$, it is widely reported for direct formic acid fuel cells and alkaline fuel cells, which are fuelled with ethanol and propanol (Antolini, 2009; Shao, 2011; Shao et al., 2011). Pd and its alloys with transition metals are also widely investigated recently as electrocatalysts for ORR. Therefore, it is imperative to study its size, and shape-dependent electrochemical properties.

The kinetics of electrochemical reactions depends on the exposed crystallographic planes and the type of exposed active sites on the catalyst surface. Thus, many research groups investigated electrooxidation of organic molecules (formic acid, carbon monoxide, methanol etc.), hydrogen evolution, and oxygen reduction on low-index crystallographic planes of $\mathrm{Pt}$ and Pd (Housmans and Koper, 2003; Hoshi et al., 2006; SollaGullón et al., 2008; Grozovski et al., 2010; Farias et al., 2014). In particular, the kinetics of ORR was found to be dependent on the exposed crystallographic planes $(\{\mathrm{hkl}\})$ as reported with single crystal Pt and Pd surfaces and on electronic factors decided by the surface, subsurface and bulk compositions (Marković et al., 1994, 1995, 1997; Stamenkovic et al., 2002, 2006; Kondo et al., 2009). Furthermore, the kinetics of ORR on such well-defined surfaces is known to be influenced by the adsorption of anions such as $\mathrm{OH}^{-}, \mathrm{ClO}_{4}^{-}$, and $\mathrm{HSO}_{4}^{-}$ions from $\mathrm{NaOH}, \mathrm{HClO}_{4}$, and $\mathrm{H}_{2} \mathrm{SO}_{4}$ electrolyte medium, respectively.

The findings that established crystallographic orientation dependent ORR activity with well-defined surfaces have rarely been translated to bulk practical electrocatalysts. Shapecontrolled nanoparticles surface terminated with facets of most active sites can be used to take advantage of the facetdependence of electrochemical reaction. Therefore, many research groups shifted their focus toward shape-controlled $\mathrm{Pt}$ and Pd nanoparticles, where, one can exploit the active site dependence of ORR by populating the selective crystallographic orientations. The key to achieve shape-controlled synthesis involves enhancing or inhibiting the growth along certain crystallographic directions, either by introducing surface energy differences in the seeds of the particles, or by preferential bonding of surfactants. The strong binding of the stabilizing agent/surfactant on the catalyst surface severely hampers the catalytic activity. Therefore, removal of the surfaceadsorbed stabilizing agents after the synthesis (cleaning of the nanoparticles) is a crucial requirement, especially in the context of electrocatalytic applications.

The other issues debated over the last few decades are the stability and durability of metal nanoparticles, in particular that of $\mathrm{Pt}$ and $\mathrm{Pd}$ nanoparticle surfaces in electrochemical environment (or in the presence of adsorbates) (Clavilier and Armand, 1986; Wagner and Ross, 1988; Kolb, 1995). Previous studies have shown that the loss of electrochemical surface area (ESA) of metal nanoparticles limits the long-term performance (durability) of PEMFCs (Ferreira et al., 2005; Bi et al., 2007; Shao-Horn et al., 2007; Tripkovic et al., 2008). Two processes are believed to contribute significantly to the ESA loss of Pt nanoparticles in PEMFCs: (i) coarsening of Pt nanoparticles by the dissolution and redeposition of particles (Ostwald Ripening) and (ii) loss of Pt mass from the cathode (dissolution) (Ferreira et al., 2005; Yasuda et al., 2006; Bi et al., 2007; Shao-Horn et al., 2007). Before investigating with the real/bulk catalysts used in fuel cells, researchers studied reconstruction of the welldefined surfaces in contact with an aqueous electrolyte medium. Nevertheless, attempts to translate the findings from studies on single crystal electrodes to bulk practical electrocatalysts have met with several challenges.

Therefore, this review aims to briefly discuss the shapecontrolled synthesis of Pt and Pd nanoparticles, their cleaning methods, characterization and electrocatalytic activity toward ORR. The synthesis and cleaning of shape-controlled Pt and Pd have several commonalities; in this context, we have included both. This is rather a fundamental review and device level characteristics are not discussed. The effect of geometric and electronic factors on ORR with shape-controlled nanoparticles is discussed in detail and compared with that of single crystal surfaces. Comprehensive views are presented regarding the stability, durability and non-recoverable ESA loss of Pt shapecontrolled nanoparticles under electrochemical conditions; their implications in electrocatalytic applications are also presented.

\section{SYNTHESIS}

\section{Shape-Controlled Pt Nanoparticles}

Over the past few decades, shape-controlled metal nanoparticles [e.g., platinum cuboctahedral (Pt-CO), platinum nanocube (Pt$\mathrm{NC}$ ), platinum tetrahedral (Pt-TD), and platinum polycrystalline (Pt-PC)] were synthesized by various synthesis protocols (Tao et al., 2008; Xia et al., 2009; Lee et al., 2012a,b; Zhou and Li, 2012; Quan et al., 2013) and several excellent reviews and reports are available on these methods (Burda et al., 2005; Guo and Wang, 2011; Chen et al., 2012; Gou et al., 2013; Zhang et al., 2013; Weiner et al., 2015; Xia et al., 2015, 2017; Gilroy et al., 2018). Herein, we have briefly discussed synthesis methods (see the Table 1) considering the applications of shape-controlled nanoparticles in the electrocatalysis of ORR. Controlling the nucleation processes during the synthesis is the key step in achieving mono-disperse shape-controlled nanoparticles. The overgrowth step can be controlled by (i) reducing agents/foreign metal ions (ii) organic capping agents, and (iii) inorganic capping agents (Lee, 2014).

Using Ag ions, gaseous $\mathrm{CO}$, or halide ions as foreign additives, Pt nanoparticles with uniform shape and size were synthesized (Lee, 2014). Excess amount of Ag ions was reported to convert cubes to cuboctahedra to octahedra (Lee, 2014). Halide ions such as $\mathrm{I}^{-}$and $\mathrm{Cl}^{-}$induced formation of cubic and octahedral Pt nanoparticles, respectively (Lee, 2014). However, removal of these additives is a daunting task and thus the ORR activity obtained from such Pt nanoparticles were 
TABLE 1 | Description of synthesis of shaped-controlled Pt and Pd NPS.

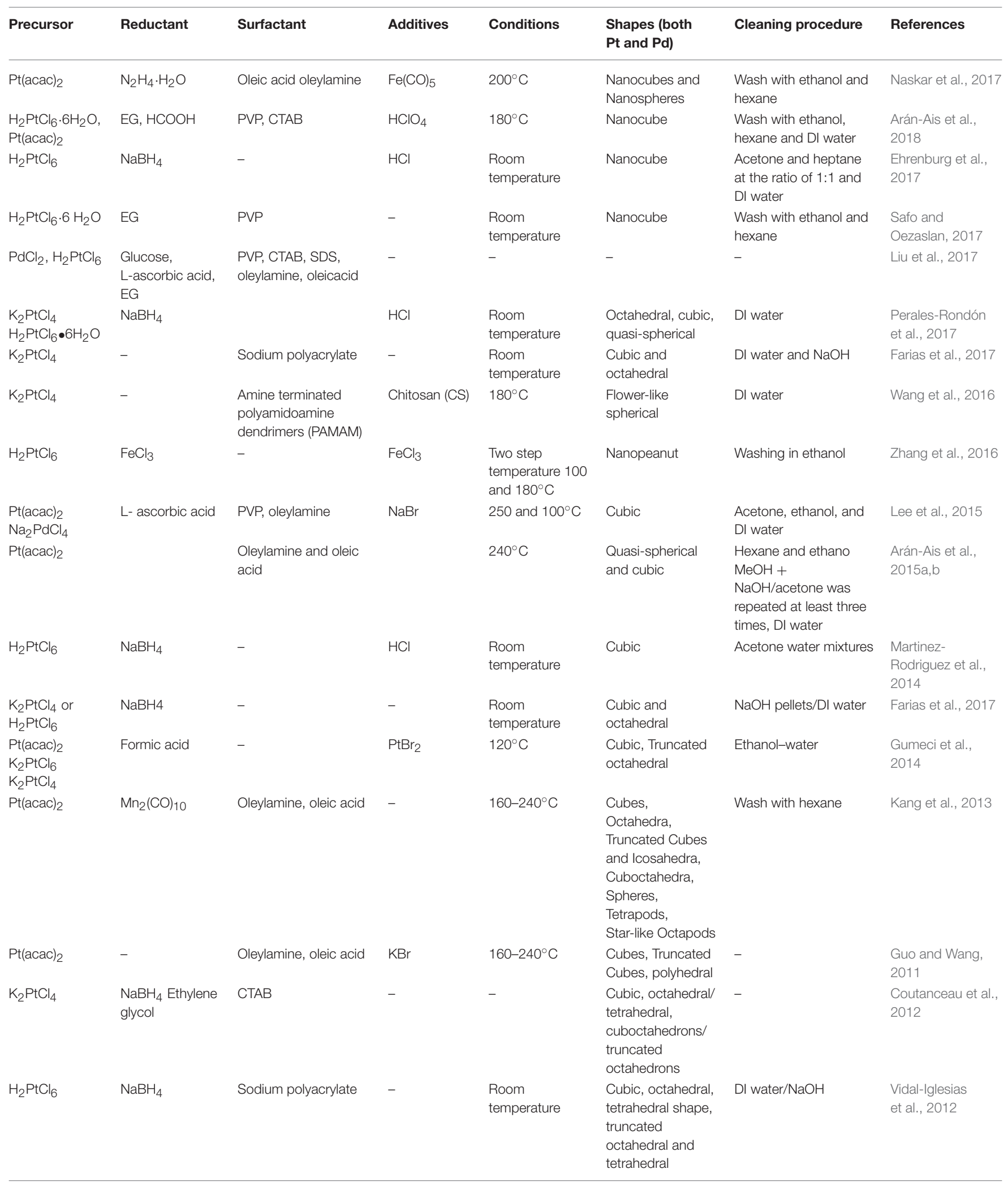


TABLE 1 | Continued

\begin{tabular}{|c|c|c|c|c|c|c|c|}
\hline Precursor & Reductant & Surfactant & Additives & Conditions & $\begin{array}{l}\text { Shapes (both } \\
\text { Pt and Pd) }\end{array}$ & Cleaning procedure & References \\
\hline $\mathrm{PdCl}_{2}$ & $\begin{array}{l}\text { L-ascorbic acid, } \\
\mathrm{NaBH}_{4}\end{array}$ & CTAB, CTAC & $\mathrm{Nal}, \mathrm{Kl}, \mathrm{NaBr}$ & $95^{\circ} \mathrm{C}$ & $\begin{array}{l}\text { Cubic and } \\
\text { Octahedral }\end{array}$ & DI water & Sneed et al., 2012 \\
\hline $\mathrm{H}_{2} \mathrm{PtCl}_{6} \cdot \times \mathrm{H}_{2} \mathrm{O}$ & $\begin{array}{l}\mathrm{NaBH}_{4} \\
\text { ascorbic acid }\end{array}$ & - & - & $\begin{array}{l}\text { Room } \\
\text { temperature }\end{array}$ & $\begin{array}{l}\text { cubic, multipods, } \\
\text { bipyramid }\end{array}$ & DI water & Ruan et al., 2011 \\
\hline $\mathrm{Na}_{2} \mathrm{PdCl}_{4}$ & L-Ascorbic acid & $\begin{array}{l}\text { Poly(vinyl pyrrolidone) } \\
\text { (PVP) }\end{array}$ & $\mathrm{KBr}$ and $\mathrm{KCl}$ & $80^{\circ} \mathrm{C}, 3 \mathrm{~h}$ & Cubes, Bars & $\begin{array}{l}\text { Washed with water for } \\
10 \text { times }\end{array}$ & Jin et al., 2011a \\
\hline $\begin{array}{l}\mathrm{K}_{2} \mathrm{PdBr}_{4} \\
\mathrm{Na}_{2} \mathrm{PdCl}_{4}\end{array}$ & $\begin{array}{l}\text { Sodium } \\
\text { adsorbate } \\
\text { (NaAsc) }\end{array}$ & PVP & $\mathrm{KBr}$ & $25^{\circ} \mathrm{C}, 3 \mathrm{~h}$ & $\begin{array}{l}\text { Concave } \\
\text { nanocubes }\end{array}$ & - & Vara and Xia, 2018 \\
\hline $\begin{array}{l}\mathrm{PdCl}_{2} \\
\left(\mathrm{CH}_{3} \mathrm{CN}\right)_{2}\end{array}$ & $\mathrm{H}_{2}$ gas (5 bar) & $\begin{array}{l}\text { Oleylamine and oleic } \\
\text { acid }\end{array}$ & - & $25^{\circ} \mathrm{C}, 1 \mathrm{~h}$ & Tripod & $\begin{array}{l}\text { Methanol followed by } \\
\text { dichloromethane and } \\
\text { toluene. }\end{array}$ & Watt et al., 2009 \\
\hline $\mathrm{H}_{2} \mathrm{PdCl}_{4}$ & L-Ascorbic acid & $\begin{array}{l}\text { Cetyltrimethylammonium } \\
\text { bromide (CTAB) }\end{array}$ & & $\begin{array}{l}30-80^{\circ} \mathrm{C}, 40 \\
\min -1 \mathrm{~h}\end{array}$ & $\begin{array}{l}\text { Cube, } \\
\text { Octahedron, and } \\
\text { RD }\end{array}$ & - & Niu et al., 2010 \\
\hline $\mathrm{Pd}(\mathrm{acac})_{2}$ & Formaldehyde & Oleylamine & - & $100^{\circ} \mathrm{C}, 8 \mathrm{~h}$ & $\begin{array}{l}\text { Icosahedron, } \\
\text { decahedron, } \\
\text { octahedron, } \\
\text { tetrahedron, and } \\
\text { triangular plates }\end{array}$ & $\begin{array}{l}\text { Acetic acid treatment } \\
\text { at } 70^{\circ} \mathrm{C} \text { for } 10 \mathrm{~h}\end{array}$ & $\begin{array}{l}\text { Mazumder and } \\
\text { Sun, 2009; Niu } \\
\text { et al., } 2011\end{array}$ \\
\hline $\begin{array}{l}\mathrm{Na}_{2} \mathrm{PdCl}_{4} \text { and } \\
\mathrm{Pd}(\text { acac })_{2}\end{array}$ & $\begin{array}{l}\text { Tetraethylene } \\
\text { glycol (TTEG) }\end{array}$ & PVP & - & $140^{\circ} \mathrm{C}, 1 \mathrm{~h}$ & $\begin{array}{l}\text { Cuboctahedral, } \\
\text { octahedrons, and } \\
\text { tetrahedrons }\end{array}$ & $\begin{array}{l}\text { Washing with Acetone } \\
\text { and Water for three } \\
\text { times }\end{array}$ & Wang et al., 2013 \\
\hline $\mathrm{Na}_{2} \mathrm{PdCl}_{4}$ & Diethylene glycol & PVP & $\begin{array}{l}\mathrm{Na}_{2} \mathrm{SO}_{4} \text { and } \\
\mathrm{HCl}\end{array}$ & $105^{\circ} \mathrm{C}, 3 \mathrm{~h}$ & $\begin{array}{l}\text { Decahedra and } \\
\text { Icosahedra }\end{array}$ & $\begin{array}{l}\text { Once with acetone and } \\
\text { then twice with DI } \\
\text { water }\end{array}$ & Huang et al., 2014 \\
\hline $\mathrm{PdCl}_{2}$ & $\begin{array}{l}\text { Electrochemical } \\
\text { method }\end{array}$ & - & - & $25^{\circ} \mathrm{C}$ & Tetrahexhedral & & Tian et al., 2010 \\
\hline $\mathrm{Na}_{2} \mathrm{PdCl}_{4}$ & L-Ascorbic acid & PVP & $\mathrm{KBr}$ & $60^{\circ} \mathrm{C}, 3 \mathrm{~h}$ & $\begin{array}{l}\text { Concave } \\
\text { nanocube }\end{array}$ & $\begin{array}{l}\text { Washing with water for } \\
\text { three times }\end{array}$ & Jin et al., 2011b \\
\hline $\mathrm{PdCl}_{2}$ & Ascorbic acid & $\begin{array}{l}\text { Cetylpyridinium } \\
\text { chloride }\end{array}$ & $\mathrm{HCl}$ & $80^{\circ} \mathrm{C}, 1 \mathrm{~h}$ & $\begin{array}{l}\text { Nanocube, } \\
\text { cuboctahedra, } \\
\text { octahedra }\end{array}$ & $\begin{array}{l}\text { Several times with } \\
\text { ethanol }\end{array}$ & Zhang et al., 2014 \\
\hline $\mathrm{Na}_{2} \mathrm{PdCl}_{4}$ & $\begin{array}{l}\text { Ascorbic acid, } \\
\text { Diethylene glycol }\end{array}$ & PVP & $\begin{array}{l}\mathrm{Nal}, \mathrm{FeCl}_{3}, \\
\mathrm{Na}_{2} \mathrm{SO}_{4} \\
\mathrm{NaCl}\end{array}$ & $104^{\circ} \mathrm{C}, 3 \mathrm{~h}$ & $\begin{array}{l}\text { Decahedra, } \\
\text { nanorod }\end{array}$ & $\begin{array}{l}\text { Three times with } \\
\text { acetone and water }\end{array}$ & $\begin{array}{l}\text { Ruditskiy et al., } \\
2017\end{array}$ \\
\hline $\mathrm{PdCl}_{2}$ & $\begin{array}{l}\text { Ascorbic acid, } \\
\text { sodium } \\
\text { borohydride, }\end{array}$ & $\begin{array}{l}\text { CTAB (NaBr), and } \\
\text { (CTAC) }\end{array}$ & $\mathrm{HCl}$ & $30^{\circ} \mathrm{C}, 10 \mathrm{~min}$ & $\begin{array}{l}\text { Nanocube, } \\
\text { concave } \\
\text { nanocube, } \\
\text { nanoflowere }\end{array}$ & & $\begin{array}{l}\text { Sreedhala et al., } \\
2014\end{array}$ \\
\hline $\mathrm{PdCl}_{2}$ & Ascorbic acid & CTAB & $\begin{array}{l}\left(\mathrm{CuSO}_{4}\right), \\
\left(\mathrm{CuCl}_{2}\right), \\
\left(\mathrm{Cu}\left(\mathrm{NO}_{3}\right)_{2}\right), \\
\mathrm{HCl}\end{array}$ & $95^{\circ} \mathrm{C}, 12 \mathrm{~h}$ & $\begin{array}{l}\text { Nanocubes, } \\
\text { concave } \\
\text { nanocubes }\end{array}$ & Two times with water & Niu et al., 2014 \\
\hline $\mathrm{PdCl}_{2}$ & Ascorbic acid & CTAB, CTAC & & $30^{\circ} \mathrm{C}, 7 \mathrm{~h}$ & $\begin{array}{l}\text { Concave } \\
\text { nanocubes }\end{array}$ & $\begin{array}{l}\text { Electrochemical } \\
\text { cleaning }\end{array}$ & Zhang et al., 2011 \\
\hline $\mathrm{PdCl}_{2}$ & Ascorbic acid & CTAC & $\mathrm{KBr}, \mathrm{Kl}$ & $30-60^{\circ} \mathrm{C}, 30 \mathrm{~min}$ & $\begin{array}{l}\text { Nanocubes, } \\
\text { concave } \\
\text { nanocubes, } \\
\text { octahedral, } \\
\text { truncated } \\
\text { octahedral, } \\
\text { cuboctahedral }\end{array}$ & Washing with water & Liu et al., 2015 \\
\hline $\mathrm{K}_{2} \mathrm{PdCl}_{4}$ & Ascorbic acid & CTAB & & $35-40^{\circ} \mathrm{C}$ & $\begin{array}{l}\text { Concave } \\
\text { nanocubes }\end{array}$ & Washing with water & Xie et al., 2015 \\
\hline $\mathrm{Na}_{2} \mathrm{PdCl}_{4}$ & Ascorbic acid & PVP & $\mathrm{KBr}, \mathrm{KCl}$ & $\begin{array}{l}25^{\circ} \mathrm{C}, 3 \mathrm{~h} \text { under } \\
\text { UV-visible } \\
\text { irradiation }\end{array}$ & $\begin{array}{l}\text { Truncated cubes, } \\
\text { cubes }\end{array}$ & Acetic acid washing & Vara et al., 2017 \\
\hline
\end{tabular}


TABLE 1 | Continued

\begin{tabular}{|c|c|c|c|c|c|c|c|}
\hline Precursor & Reductant & Surfactant & Additives & Conditions & $\begin{array}{l}\text { Shapes (both } \\
\text { Pt and Pd) }\end{array}$ & Cleaning procedure & References \\
\hline $\mathrm{Na}_{2} \mathrm{PdCl}_{4}$ & $\begin{array}{l}\text { Ascorbic acid, } \\
\text { Diethylene } \\
\text { glycol, Ethylene } \\
\text { glycol, } \\
\text { Formaldehyde, } \\
\text { Citric acid }\end{array}$ & PVP & $\begin{array}{l}\mathrm{Nal}, \mathrm{KBr}, \mathrm{KCl} \\
\mathrm{HCl}\end{array}$ & $\begin{array}{l}80^{\circ} \mathrm{C}, 3 \mathrm{~h} \\
160^{\circ} \mathrm{C}, 1 \mathrm{~h}\end{array}$ & $\begin{array}{l}\text { Nanowires, } \\
\text { nanocubes }\end{array}$ & $\begin{array}{l}\text { One time with acetone, } \\
\text { two times with water }\end{array}$ & Peng et al., 2016 \\
\hline $\mathrm{H}_{2} \mathrm{PdCl}_{4}$ & $\begin{array}{l}\text { Carbon } \\
\text { monoxide (CO) }\end{array}$ & - & $\mathrm{CO}$ & $\begin{array}{l}\text { Ambient } \\
\text { temperature, } \\
30 \text { min }\end{array}$ & Nanosheets & $\begin{array}{l}\text { Organic ligand free } \\
\text { synthesis }\end{array}$ & Li et al., 2013 \\
\hline $\mathrm{H}_{2} \mathrm{PdCl}_{4}$ & Ascorbic acid & CTAB & $\mathrm{KI}$ & $95^{\circ} \mathrm{C}, 30 \mathrm{~min}$ & $\begin{array}{l}\text { Rhombic } \\
\text { dodecahedral, } \\
\text { Cubic }\end{array}$ & $\begin{array}{l}\text { Repeated CO } \\
\text { adsorption replacement } \\
\text { and anodic stripping }\end{array}$ & Zhang et al., 2012 \\
\hline $\mathrm{K}_{2} \mathrm{PdCl}_{4}$ & $\mathrm{NaBH}_{4}$ & CTAB & - & $30^{\circ} \mathrm{C}, 2 \mathrm{~h}$ & $\begin{array}{l}\text { Pyramid, } \\
\text { pentatwinned } \\
\text { nanorods, cube, } \\
\text { icosahedra }\end{array}$ & - & Bisson et al., 2009 \\
\hline $\begin{array}{l}\mathrm{Na}_{2} \mathrm{PdCl}_{4} \\
\mathrm{PdCl}_{2}\end{array}$ & Ascorbic acid & $\begin{array}{l}\text { Cinchonidin, S-proline } \\
\text { CTAB, PVP }\end{array}$ & $\mathrm{HCl}$ & $\begin{array}{l}50-95^{\circ} \mathrm{C}, 20 \\
\min -3 \mathrm{~h}\end{array}$ & $\begin{array}{l}\text { Nanocube, } \\
\text { nanodendrite }\end{array}$ & $\begin{array}{l}\text { Washed by water once } \\
\text { and methanol twice }\end{array}$ & Gao et al., 2019 \\
\hline $\mathrm{K}_{2} \mathrm{PdCl}_{4}$ & $\mathrm{NaBH}_{4}$ & $\begin{array}{l}\text { Dodecanethiol (DDT), } \\
\text { oleylamine (OAm), and } \\
\text { PVP }\end{array}$ & - & $60-90^{\circ} \mathrm{C}, 3 \mathrm{~h}$ & Polycrystalline & $\begin{array}{l}\text { Thermal treatment } \\
\text { Chemical treatments }\end{array}$ & Collins et al., 2018 \\
\hline $\mathrm{H}_{2} \mathrm{PdCl}_{4}$ & L-Ascorbic acid & \multicolumn{2}{|c|}{$\begin{array}{l}\text { Dioctadecyldimethylammonium } \\
\text { chloride (DODAC) }\end{array}$} & $95^{\circ} \mathrm{C}, 30 \mathrm{~min}$ & Nanowires & $\begin{array}{l}\text { UV/Ozone treatment } \\
\text { for } 2 \mathrm{~h}\end{array}$ & Xu et al., 2016 \\
\hline
\end{tabular}

significantly lower than that of the commercial Pt-PC catalyst from Jhonson Mattey.

A short review by Mourdikoudis and Liz-Marzán (2013) reported on all the important aspects of the suitability and the versatility of oleylamine/oleic acid (OAm/OAc) reaction medium for the synthesis of a broad range of nanoscale materials. Since the primary focus of this review is something different, extensive details of the synthesis is avoided.

Essentially, it was established that OAm and OAc work in combination to produce several different shaped nanoparticles under specific experimental conditions. Importantly, it was identified that the composition of OAm/OAc plays a crucial role in deciding the final morphology of nanoparticles. OAm is long-chain primary alkylamine, which acts as electron donor, exhibits basicity and affinity to metals through their $\mathrm{NH}_{2}$ functional groups, and the resulting morphology and crystallinity of the produced nanoparticles can be significantly different based on the solvent, surfactant and reducing agent. Moreover, OAm is a liquid at room temperature, which may simplify the washing procedures, following the chemical synthesis of nanoparticles. Other advantages of the use of OAm are its easy removal via centrifugation, high boiling point, low cost and tendency to form metal-OAm complexes at intermediate temperatures, so that it can be controllably decomposed to produce nanoparticles. On the other hand, OAc with carboxylic acid functional groups induces the structural changes in the nanoparticles. The composition, size and shape of the obtained nanoparticles can be tuned by careful choice of additional reaction parameters, depending on the system under study. Thus, two of the most popular organic reagents used for the shapecontrol are oleic acid and oleylamine (Chen et al., 2009). Organic reagents help prevent aggregation of nanoparticles during the synthesis and a variety of shapes (cubes, tripods, octapods, prisms, rods etc.) of Pt nanoparticles were synthesized. In particular, amine-containing capping agents are widely used in the shape-controlled synthesis because of the strong interaction between nitrogen and Pt surface. For e.g., using adamantane carboxylic acid (ACA) and hexadecylamine (HDA) as capping agents, Pt cubes, tripods and multipods were prepared (Chen et al., 2009).

Shape-controlled Pt nanoparticles were also synthesized using various other surfactants and capping agents (citric acid, polyvinylpyrrolidone (PVP), cetyl trimethylammonium bromide (CTAB), ascorbic acid, etc.) (Chen et al., 2009; Peng and Yang, 2009; Chun-Jiang and Schuth, 2011). Most importantly, Ahmadi et al. (1996) reported the synthesis of cubic, tetrahedral and cuboctahedral Pt nanoparticles, surface-terminated with lowindex facets. For e.g., cubic shape is bound by $\{100\}$ planes, cuboctahedron by a mix of $\{111\}$ and $\{100\}$ planes, and icosahedron by $\{111\}$ planes. Ahmadi et al. (1996) reported chemical reduction of $\mathrm{K}_{2} \mathrm{PtCl}_{4} / \mathrm{H}_{2} \mathrm{PtCl}_{6}$ of specific composition by $\mathrm{H}_{2}$ in the presence of polyacrylate (PAA) to produce shape-controlled Pt nanoparticles. Figure 1 shows the HRTEM images of shape-controlled Pt nanoparticles obtained with one such method. Because of the easinesss with the experimental conditions and the PAA surfactant removal method, later on, many researchers employed similar synthesis procedures to obtain various $\mathrm{Pt}$ shape-controlled nanoparticles by changing the respective precursors, reduction conditions with $\mathrm{H}_{2}$, and the 

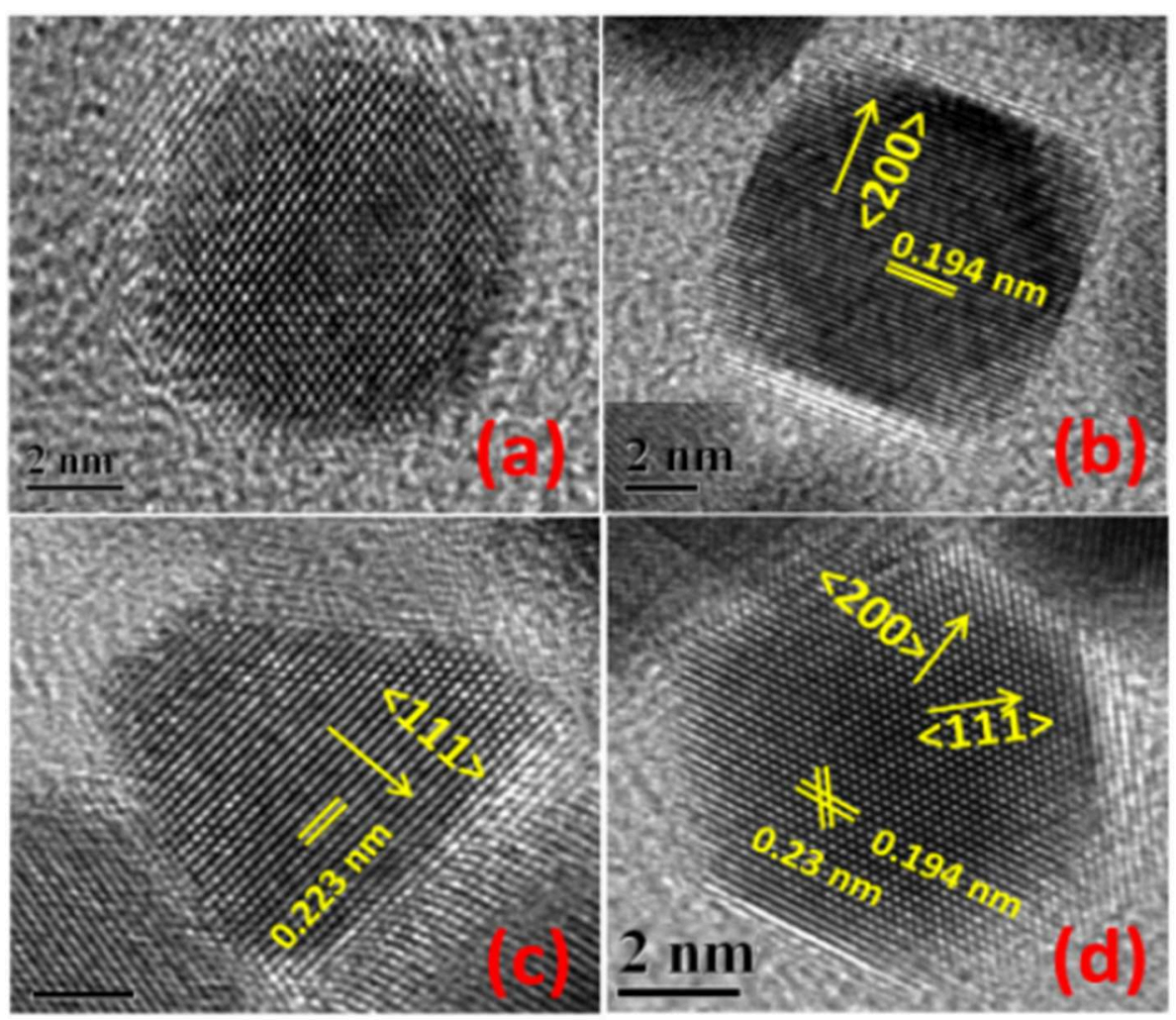

FIGURE 1 | HR-TEM images of single Pt-PC (a), Pt-NC (b), Pt-TD (c), and Pt-CO (d) nanoparticles. Reproduced and modified with permission (Devivaraprasad et al. 2014). Copyright 2014, American Chemical Society (ACS).

concentration of the PAA (Ahmadi et al., 1996; Solla-Gullón et al., 2003, 2008; Chen et al., 2009). Henceforth, in electrocatalysis of ORR, emphasis has been on enhancing the activity and durability of shape-controlled nanoparticles, and in understanding their relevance toward the practical electrocatalysts employed in fuel cell application.

\section{Shape-Controlled Pd Nanoparticles}

Different morphologies of Pd were obtained by changing the Pd precursor concentration during the electrodeposition, for e.g., Pd nanorods with dominant (110) facets were obtained from $3 \times$ $10^{-4} \mathrm{M} \mathrm{PdCl}_{2}$ and Pd nanoparticles with (100), and (111) facets and other disordered structures from $3 \times 10^{-5} \mathrm{M} \mathrm{PdCl}_{2}$ (Xiao et al., 2009). The synthesis of Pd nanocubes of size $\sim 30 \mathrm{~nm}$ was carried out using CTAB as structural control agent, ascorbic acid as reducing agent and $\mathrm{H}_{2} \mathrm{PdCl}_{4}$ as the metal precursor. Besides, Pd polycrystalline (Pd-PC) nanoparticles $(\sim 3 \mathrm{~nm})$ were prepared using $\mathrm{NaBH}_{4}$ and sodium citrate as reducing agent and stabilizer, respectively (Erikson et al., 2011).

Seed-mediated synthesis is also a powerful strategy to produce colloidal metal nanocrystals. Under controlled experimental conditions, this approach enables reproducible synthesis of nanoparticles, minimizing wastage of reagents. It offers a facile method to engineer the surface of the nanoparticle; in general, the facets of the end product replicates the surface structure of the initial seed. It allows to tune the surface of nanostructure using the capping agents present in the solution.

The preparation of shape-controlled metal nanoparticles using surfactant-free or weakly adsorbed capping ligands those can easily be removed is particularly attractive for electrocatalytic ORR. In this context, $\mathrm{Cl}^{-}$ion mediated shape-control of $\mathrm{Pd}$ nanoparticles was achieved by changing concentrations of $\mathrm{Cl}^{-}$ ions, the synthesis temperature, and the reaction atmosphere (argon, air, and oxygen); it is possible to control the shape and size of Pd nanoparticles (Nalajala et al., 2016). The study emphasized that $\mathrm{Cl}^{-}$ions can control the shape of $\mathrm{Pd}$ and can produce nanocubes of size $\sim 8 \mathrm{~nm}$ from solution with dissolved oxygen content, as shown in Figure 2. Under appropriate experimental conditions, with the help of $\mathrm{Cl}^{-}$ions as capping agent, various shapes of Pd such as nanocube, octahedral, multiple twinned particles (MTP), and nanorods were obtained. The shapecontrol of Pd using strongly adsorbing $\mathrm{Br}^{-}$and $\mathrm{I}^{-}$ions were also investigated and it was found that the dissolved oxygen could not affect the shape of Pd nanoparticles (Nalajala et al., 2016).

Nanosheets of different thickness ( 3 monolayers (ML), $5 \mathrm{ML}$, $8 \mathrm{ML}$ ) and of different edge length (ranging from $\sim 120$ to $\sim 260 \mathrm{~nm}$ ) were prepared using $\mathrm{CO}$ as a reducing as well as stabilizing ligand and oleylamine as solvent (Wang et al., 2019). For the first time, the hydride form of $\mathrm{Pd}$ nanocubes $\left(\mathrm{PdH}_{\mathrm{X}}\right.$ for $\mathrm{x}=0,0.43,0.706)$ was established for $\mathrm{ORR}$ in $\mathrm{O}_{2}$-saturated 


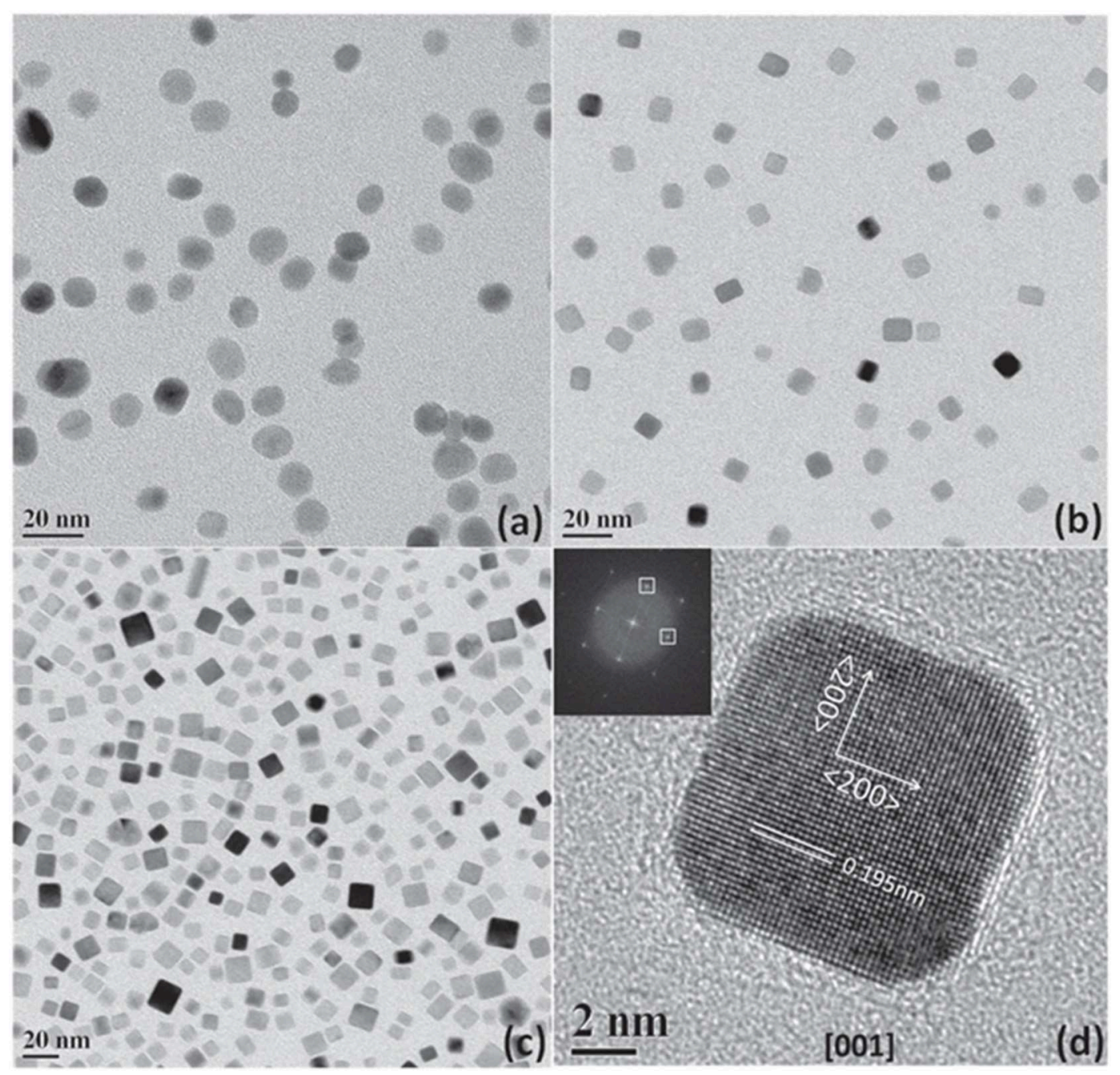

FIGURE 2 | TEM images of Pd nanoparticles using $\mathrm{Cl}^{-}$ions as capping agent under different atmospheres: (a) in ambient air; (b) in $\mathrm{Ar}$; (c) in $\mathrm{Ar}$ at $80^{\circ} \mathrm{C}$; and (d) the HRTEM image of selected nanoparticle; inset of (c) shows FFT of that nanoparticle. Reproduced with permission (Nalajala et al., 2016). Copyright 2016, Institute of Physics (IOP).

$0.1 \mathrm{M} \mathrm{HClO}_{4}$ electrolyte. The proposed nanostructures were prepared using autoclave method with DMF as a solvent, PVP as a stabilizer, $\mathrm{NaI}$ as a capping agent and $\mathrm{Pd}(\mathrm{II})$ acetylacetonate as a precursor (Lu et al., 2017). The Pd-NCs dominant with (100) facets and rhombic dodecahedron dominant with (110) facets were prepared using an aqueous one-pot synthesis method. In the preparation of these nanostructures at $90^{\circ} \mathrm{C}, \mathrm{KI}$ was used as capping agent and CTAB was the stabilizing agent at different concentrations (Tang et al., 2016).

The capping agent may simply be a liberated byproduct or it can also be intentionally added during a solution-phase synthesis to control the shape of a nanoparticle. Through its chemical interaction with a metal surface, the presence of a capping agent can change free energies of different crystallographic planes, and thus their relative growth rates. Generally speaking, the binding affinity of a capping agent can vary from one crystal facet to another. Such preferential capping can effectively hinder the growth of a particular facet, thus providing a means for controlling the relative surface areas of different facets.

For e.g., PVP, a polymeric capping agent, binds strongly to the $\{100\}$ facets of Ag and Pd through oxygen atoms. This preferential capping can drive the addition of metal atoms to the other crystal facets when crystal seeds are suitably large. Thus, for singlecrystal seeds terminated with only $\{111\}$ and $\{100\}$ facets, metal atoms will add preferentially to the poorly passivated $\{111\}$ facets (Xia et al., 2009). In contrast, PVP, $\mathrm{Br}^{-}$, and citrate ions bind most strongly to $\{111\}$ facets, thus favoring the formation of octahedrons, icosahedrons, and decahedrons. The use of capping agents to control the shape of a nanoparticles makes some facets thermodynamically more favorable by reducing their interfacial free energies through chemisorption. Though the capping agents play a vital role in controlling the shape of nanoparticles, a complete understanding of the mechanism of shape-control still remains elusive. 


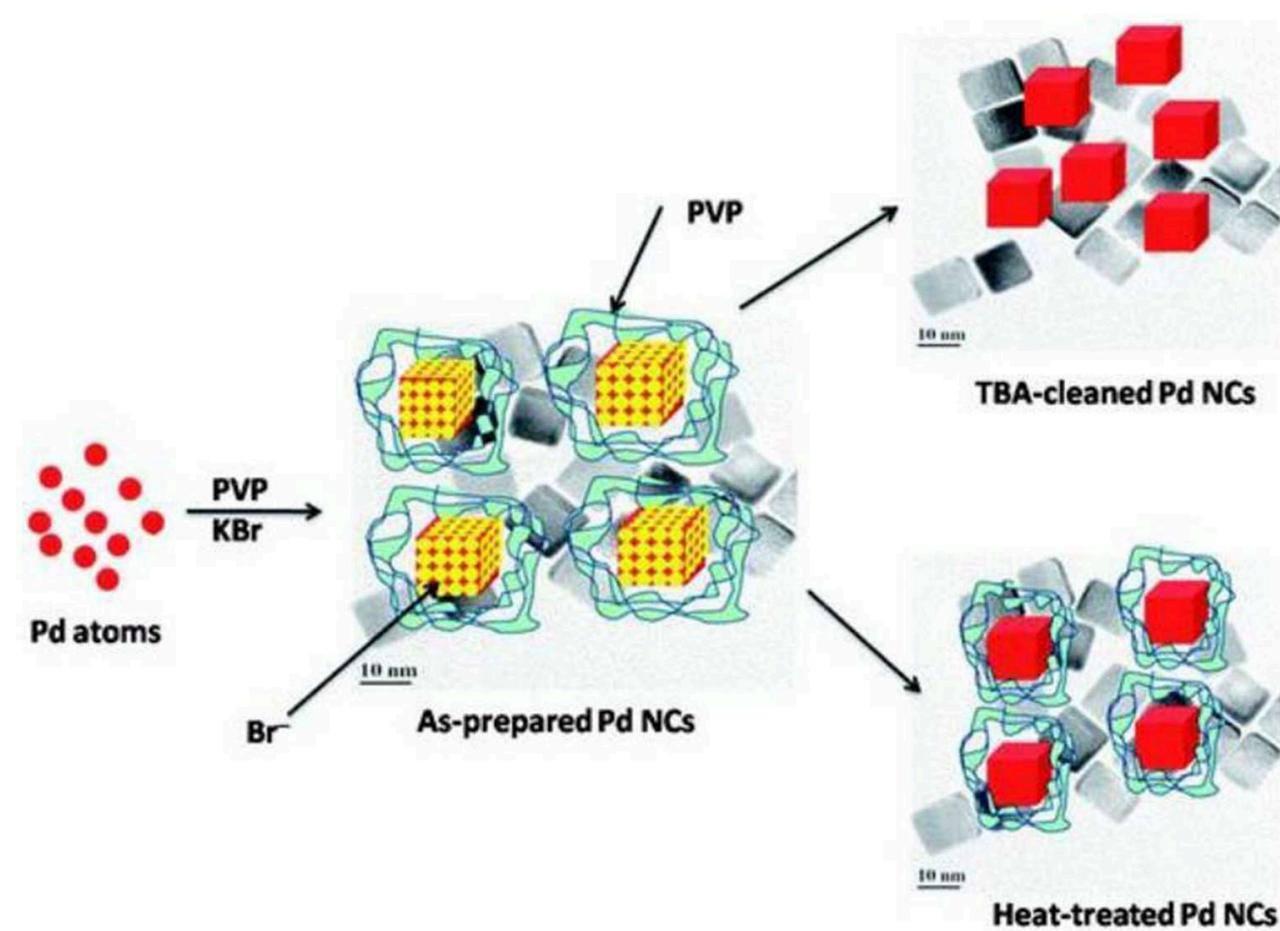

FIGURE 3 | Scheme proposed for the removal of PVP and $\mathrm{Br}^{-}$ions using TBA treatment and heat treatment. Reproduced with permission (Nalajala et al., 2013). Copyright 2013, Royal Society of Chemistry (RSC).

\section{SURFACTANT REMOVAL METHODS}

\section{Shape-Controlled Pt Nanoparticles}

Nanoparticles contaminated with impurities, from the reagents used for the synthesis (e.g., capping agents and surfactants), cannot be directly used as electrocatalysts. It is necessary to clean the nanoparticles before subjecting them to ORR studies because of the coverage of active sites with organic ligands those were used to control size, shape and composition. Such clean nanoparticles are important in deriving any conclusions related to surface orientation. Therefore, it is imperative to develop methods for the removal of impurities without disturbing the size, shape, composition, and most importantly the surface structure of target nanoparticles.

Literature is replete with procedures for the removal of organic impurities from the surface of the particle and that involve thermal annealing, UV-ozone irradiation, and acid wash (Vig, 1985; Aliaga et al., 2009; Crespo-Quesada et al., 2011; Long et al., 2011; Monzo et al., 2012; Niu and Li, 2014; Niu et al., 2014; Yang et al., 2014; Arán-Ais et al., 2015a). The UV/ozone cleaning procedure can remove impurities from the particle surfaces in air or in vacuum atmosphere at room temperature in less than a minute. The surface cleanliness of nanoparticles was evidenced by the Auger electron spectroscopy, Electron Spectroscopy for Chemical Analysis (ESCA), and Ion Scattering Spectroscopy/Secondary Ion Mass Spectrometry (ISS/SIMS) studies (Vig, 1985). Aliaga et al. (2009) reported the removal of PVP and TTAB from Pt nanoparticles by the UVozone cleaning method. The effectiveness of this method was confirmed by several analytical measurements including Sum Frequency Generation Vibrational Spectroscopy (SFGVS), Xray Photoelectron Spectroscopy (XPS) and Diffuse Reflectance Infrared Fourier Transform Spectroscopy (DRIFTS) (Aliaga et al., 2009). The same morphological features that were obtained from TEM of the cleaned nanoparticles and that of the as-prepared counterparts demonstrated that the UV-ozone treatment did not affect the shape of the Pt nanoparticles.

Out of several PVP removal procedures studied, it was reported that heat treatment/thermal annealing at $300^{\circ} \mathrm{C}$ could cause structural destruction of $\mathrm{Pt}$ nanoparticles; the treated particles were synthesized using polyol method by the reduction of $\mathrm{H}_{2} \mathrm{PtCl}_{6}$ with $\mathrm{AgNO}_{3}$ and ethylene glycol (Long et al., 2011). Nevertheless, the ORR activity of such nanoparticles was shown to be inferior due to the nanoparticle aggregation. Monzo et al. (2012) reported an effective method for cleaning Pt nanoparticles capped with PVP, without affecting their surface structure. The cleaning of $\mathrm{Pt}$ nanoparticles involved mixing of colloidal solution of Pt nanoparticles with $\mathrm{H}_{2} \mathrm{O}_{2} / \mathrm{H}_{2} \mathrm{SO}_{2}$ of appropriate concentrations, followed by centrifugation for several times. The characteristic features corresponding to the presence of (111) ordered surface domains demonstrated the extent of cleanliness of Pt nanoparticles (Monzo et al., 2012). Using electrocatalytic ORR as a probe, the effectiveness of the methods for oleylamine removal from oleylamine-capped $\mathrm{Pt}$ nanoparticles was found to 
be in the order of thermal annealing at $185^{\circ} \mathrm{C}$ in air $>$ acetic acid washing $>$ UV-ozone irradiation (Niu et al., 2014).

Contrary to most of the published reports, Vidal-Iglesias et al. (2011) showed the adverse effect of UV/ozone treatment involved in the decontamination of shape-controlled Pt nanoparticles prepared with PAA-TTAB. With the help of electrochemical techniques, this group successfully demonstrated that the UV/ozone cleaning process keeps the shape intact and disturbs the surface structure. Such unintentional surface perturbations may alter the catalytic activity. They demonstrated the weakness of conventional TEM toward such changes in the surface structure while it does give evidence for the change in shape.
In addition to the methods discussed above, electrochemical procedures were also widely used for the removal of surfactants from the catalyst surface. Thus, Pt nanoparticles were cleaned by potential cycling (in the range of $0.05-1.0 \mathrm{~V}$ ) in appropriate electrolytes. Reproducible voltammograms are indication of the cleanliness. However, this procedure causes reconstruction of the surface and more details on the same will be discussed in the following sections. Solla-Gullón et al. (2003) used a modified cleaning method in sulfuric acid solution, which involves holding the electrode at $0.03 \mathrm{~V}$ for $3 \mathrm{~min}$. The electrode was subsequently subjected to potential cycling in the range of 0.04-0.4 V. After repeating the above-mentioned procedure three

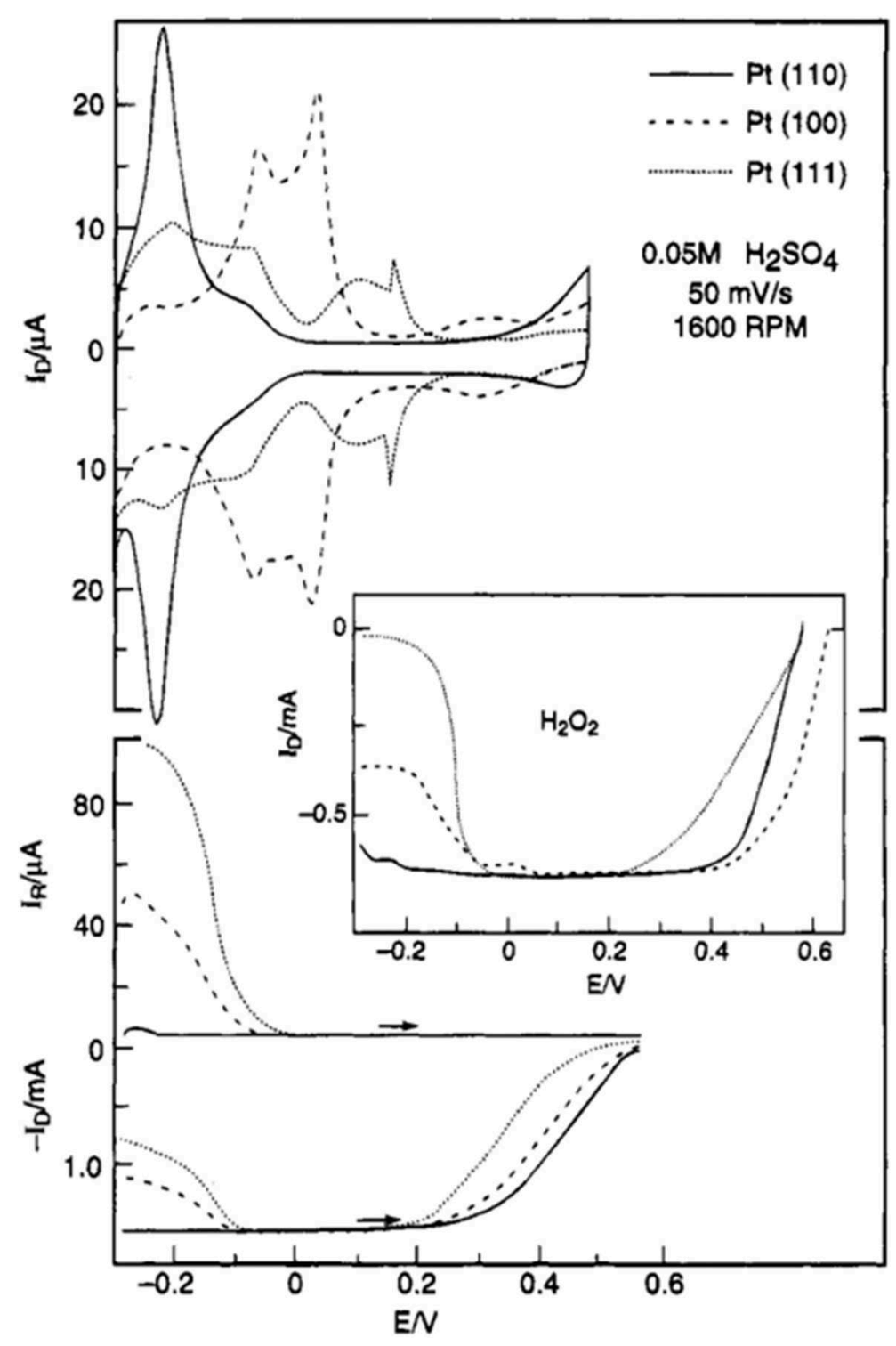

FIGURE 4 | Top: CVs of Pt(hkl) in oxygen-free electrolyte in the RRDE assembly (fifth sweep). Bottom: ORR of Pt(hkl) in oxygen-saturated electrolyte (ring potential = $0.95 \mathrm{~V})$. Insert: reduction of $1.2 \times 10^{-3} \mathrm{M} \mathrm{H}_{2} \mathrm{O}_{2}$ on Pt(hkl) mounted in the RRDE assembly $\left(0.05 \mathrm{M} \mathrm{H}_{2} \mathrm{SO}_{4}, 50 \mathrm{mV} / \mathrm{s}, 1,600 \mathrm{rpm}\right)$. Reproduced with permission (Marković et al., 1995). Copyright 1995, American Chemical Society (ACS). 
times, the cleanliness of the surface was confirmed through the systematic voltammetric analysis.

Although various cleaning protocols have been proposed and proved to be efficient enough, it is important to understand that, most of these cleaning procedures are specific to the removal of individual surfactant, stabilizer, or synthesis protocols employed; therefore, the search for universal procedure for the removal of surfactant still continues.

\section{Shape-Controlled Pd Nanoparticles}

The removal of surfactant and capping agent was demonstrated with Pd-NCs synthesized by the solution phase method at $85^{\circ} \mathrm{C}$ in which PVP (stabilizer), L-Ascorbic acid (reducing agent), $\mathrm{KBr}$ (capping agent), and $\mathrm{K}_{2} \mathrm{PdCl}_{4}$ (precursor) were used. Voltammetric features of Pd were not observed from the as-prepared Pd-NCs and it demonstrated that the catalyst surface was completely contaminated with adsorbed impurities (residual PVP and $\mathrm{Br}^{-}$). Nalajala et al. (2013) reported a process for the removal of afore-mentioned impurities from Pd-NCs on treatment with tertiary butylamine (TBA). The cleanliness of Pd-NCs was confirmed by both physical and electrochemical characterizations. The sharp $\mathrm{H}_{\text {upd }}$ features and ORR voltammograms in argon-saturated and oxygensaturated $0.1 \mathrm{M} \mathrm{HClO}_{4}$ solutions, respectively, demonstrated that the Pd-NCs were cleaned after TBA-treatment. Therefore, it was established that TBA could be a better solvent for the removal impurities from $\mathrm{Pd}-\mathrm{NCs}$, without affecting their surface structural integrity (Figure 3). TBA reacts with $\mathrm{Br}^{-}$ions to form a quaternary ammonium salt that can easily dissolve in aqueous solution and thus cause removal of $\mathrm{Br}^{-}$ions.

The same group further established processes for decontaminating stabilizer (PVP) and capping agents (citrates and halides), by exploiting the inherent property of Pd to form hydride (Nalajala et al., 2014). Thus, the exposure of as-prepared shape-controlled $\mathrm{Pd}$ nanoparticles to $\mathrm{NaBH}_{4}$ helps remove the adsorbed impurities, by weakening their interaction with the Pd metal hydride surface. The extent of cleaning after the treatment with $\mathrm{NaBH}_{4}$ was demonstrated by physical and electrochemical characterizations. Overall, weakly adsorbing reagents are preferred for shape-control of $\mathrm{Pd}$ nanoparticles because of the easy removal of impurities, without disrupting the surface structural integrity.

In order to remove the impurities from the Pd nanocubes and octahedral nanoparticle surface, steam treatment in a lab-made reactor was developed by Yang et al. (2018). The nanoparticles obtained after the steam treatment were intact with their shape and size. This steam cleaning process was reported to effectively remove adsorbed PVP from the Pd nanoparticles. Pd NCs prepared using PVP as stabilizing agent and $\mathrm{NaI}$ as capping agent were treated with ice cold $\mathrm{NaBH}_{4}$ for 30 min under vigorous stirring followed by washing with water-ethanol mixture. The basis for the removal of impurities was the formation of hydride, which in fact weakens the interaction between the impurities and metal surface, helping easy desorption from the surface ( $\mathrm{Lu}$ et al., 2017). The Pd nanoparticles those were synthesized using $\mathrm{PVP}$ as stabilizer and $\mathrm{KBr}$ and citric acid as capping agents were subjected to non-destructive methods under electrochemical conditions, by holding the electrode consisting of thin layer of nanoparticles at $-0.05 \mathrm{~V}$ vs. RHE for 60 seconds (Shao, 2011; Shao et al., 2011, 2013). After the synthesis, the prepared nanoparticles were treated with strong basic solution followed by the electrochemical oxidation of pre-adsorbed $\mathrm{CO}$ to produce clean nanoparticles (Erikson et al., 2012). Thermal annealing process at $300^{\circ} \mathrm{C}$ was implemented for the removal of surfactant (KI and CTAB) without disturbing the structural integrity of the Pd nanostructures (rhombic dodecahedral and cubic) (Tang et al., 2016). The cleaning of carbon-supported Pd-NCs of different sizes $(\sim 7, \sim 10, \sim 30 \mathrm{~nm})$ was also performed by the addition of $\mathrm{NaOH}$ pellets followed by washing the mixture with DI water (Erikson et al., 2016).

\section{STRUCTURE SENSITIVITY OF ORR WITH SINGLE CRYSTAL ELECTRODES AND SHAPE-CONTROLLED METAL NANOPARTICLES}

\section{Case of Platinum}

It was established that the ORR activity of single crystal Pt electrodes is determined by the type of kinks, steps, terraces and sites on the catalyst surface (Marković et al., 1995; Macia et al., 2004; Rizo et al., 2013; Arán-Ais et al., 2016). Figure 4 shows the work reported by Marković et al. (1995), and the ORR activity of single crystal $\mathrm{Pt}$ electrode in $0.05 \mathrm{M} \mathrm{H}_{2} \mathrm{SO}_{4}$ is in the order of $\{110\}>\{100\}>\{111\}$, and that of peroxide formation is $\{111\}>\{100\}>\{110\}$. On the other hand, the activity orders in $0.1 \mathrm{M} \mathrm{HClO}_{4}$ electrolyte (Marković et al., 1994, 1997) and that in alkaline electrolyte (Marković et al., 1995; Rizo et al., 2013) were found to be different. The difference in ORR activity trends in various electrolytes was attributed to the inhibiting effect of solution anions on different sites (Marković et al., 1995). The relatively higher activity in alkaline media (as compared to that in acidic media) was explained on the basis of lower steric hindrance offered by $\mathrm{OH}^{-}$ions (compared to complex oxy-anions, for e.g., $\mathrm{HSO}_{4}^{-}$and $\mathrm{ClO}_{4}^{-}$(Clavilier and Armand, 1986; Durst et al., 2012).

Electrochemical techniques offer detailed information on the surface structure of shape-controlled metal nanoparticles based on a large number of nanoparticles that are available on the electrode surface (Solla-Gullón et al., 2004, 2008; Chen et al., 2012; Farias et al., 2014; García-Cruz et al., 2019; Mayet et al., 2019). Voltammograms characteritic of low-index planes on the surface of Pt nanoparticles in both acidic and alkaline electrolytes were recently reported in the literature (Vidal-Iglesias et al., 2012; Devivaraprasad et al., 2014; Jukk et al., 2017). Such voltammograms of $\mathrm{Pt}$ shape-controlled nanoparticles recorded at a scan rate of $50 \mathrm{mV} \mathrm{s}^{-1}$ are shown in Figure 5 (Vidal-Iglesias et al., 2012). Since the shape-controlled nanoparticle surface is constructed with a combination of various facets of different $\mathrm{H}_{\mathrm{ads} / \mathrm{des}}$ energies, their specific $\mathrm{H}_{\text {upd }}$ features appear at different potentials. But, the potential ranges of the $\mathrm{H}_{\text {upd }}$ from lowindex planes on the Pt surface overlap, despite being structuresensitive. The distinct and unique voltammetric features in strongly adsorbing electrolytes are the fingerprint of surfacecleaned shape-controlled nanoparticles (Vidal-Iglesias et al., 


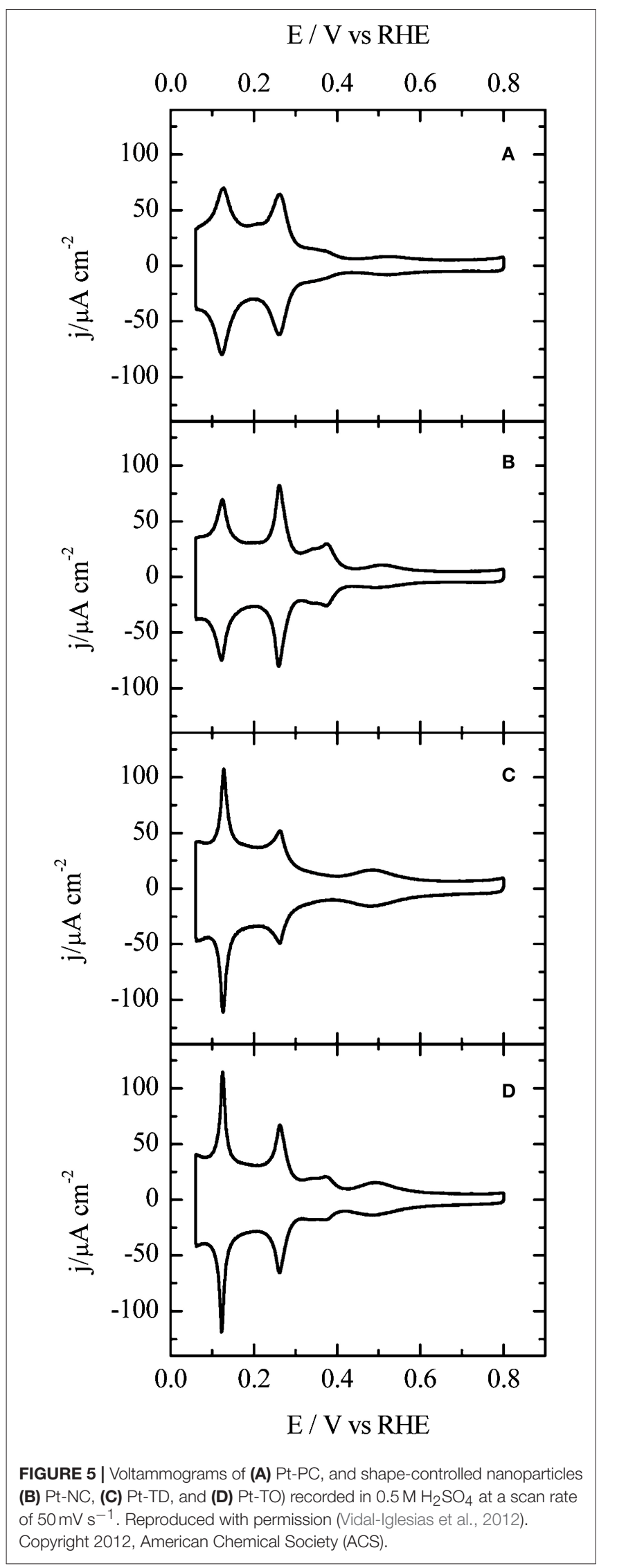

TABLE 2 | Fractions of $\{111\}$ and $\{100\}$ sites obtained using irreversible Bi and Ge adsorption, respectively, for various of shape-controlled Pt nanoparticles.

\begin{tabular}{lcc}
\hline Nanoparticles type & Bi \% $\{\mathbf{1 1 1}\}$ sites & Ge $\%\{\mathbf{1 0 0}\}$ sites \\
\hline Pt-PC & $2 \pm 1$ & $21 \pm 2$ \\
Pt-NC & $13 \pm 2$ & $52 \pm 2$ \\
Pt-TD & $60 \pm 2$ & $14 \pm 2$ \\
Pt-CO & $30 \pm 2$ & $45 \pm 2$ \\
\hline
\end{tabular}

Reproduced with permission (Devivaraprasad et al., 2014). Copyright 2014, American Chemical Society (ACS).

2012). Overall adsorption charge obtained corresponds to the number of active sites and it is a measure of ESA. As with single crystal surfaces, the sharp and characteristic voltammetric profiles can be used to characterize the surface structure (ordered domains, steps, terrreses, and basal planes) and to qualitatively assess the surface faceting of various planes on Pt shapecontrolled nanoparticles. An additional advantage is that these measurements are performed in solution, i.e., the environment in which electrochemical reactions occur and it is based on a large number of nanoparticles that are available on the electrode surface. In fact, surface atoms can undergo reconstruction and impurities modify the surface composition, and both can modify surface reactivity and have to be monitored. Therefore, it is imperative to investigate the reconstruction and dissolution of the shape-controlled nanoparticle surfaces in relevant electrolytes (electrochemical condition) to establish their stability prior to that of the reaction activity and its order. Thus, in acidic and alkaline electrolytes, the upper limit of the potential was restricted to 0.8 and $0.9 \mathrm{~V}$, repectively. Cycling to potential above $1.0 \mathrm{~V}$ leads to reconstruction of the surface and as a result loss of characteristic voltammetric features of the faceted surface of the shape-controlled nanoparticle (Devivaraprasad et al., 2014).

Using conventional voltammetric analysis, it is hard to differentiate the surface faceting with complex coordinations like terrace, steps and kinks. However, the information generated from the CVs of well-defined surface is important and can be used to get a qualitative estimate of different surface sites on Pt shape-controlled nanoparticles (Solla-Gullón et al., 2008). To get a valid correlation between faceting on nanoparticle surface and ORR activity, it is desirable to have quantitative information on various sites present on the surface. The fraction of lowindex facets on the nanoparticle surface can be obtained from the specific site-probe reactions involved in the voltammograms of irreversible adsorption of $\mathrm{Ge}$ and $\mathrm{Bi}$ on $\{100\}$ and $\{111\}$ facets, respectively (Clavilier et al., 1988; Gomez et al., 1992; Feliu et al., 1993; Rodriguez et al., 2005; Solla-Gullón et al., 2008). Table 2 presents the relative percentages of estimated low-index sites $(\{111\}$ and $\{100\})$ on shape-controlled Pt nanoparticles (Solla-Gullón et al., 2008; Devivaraprasad et al., 2014). Most importantly, such characterization of the surface structure is conducted in the same experimetal condition (electrolyte, temperature, pressure, etc) as that is used in the reaction for which the electrocatalyst is intended.

TEM provides the information on the size of the nanoparticles and fraction of various shapes present (shape selectivity) in 


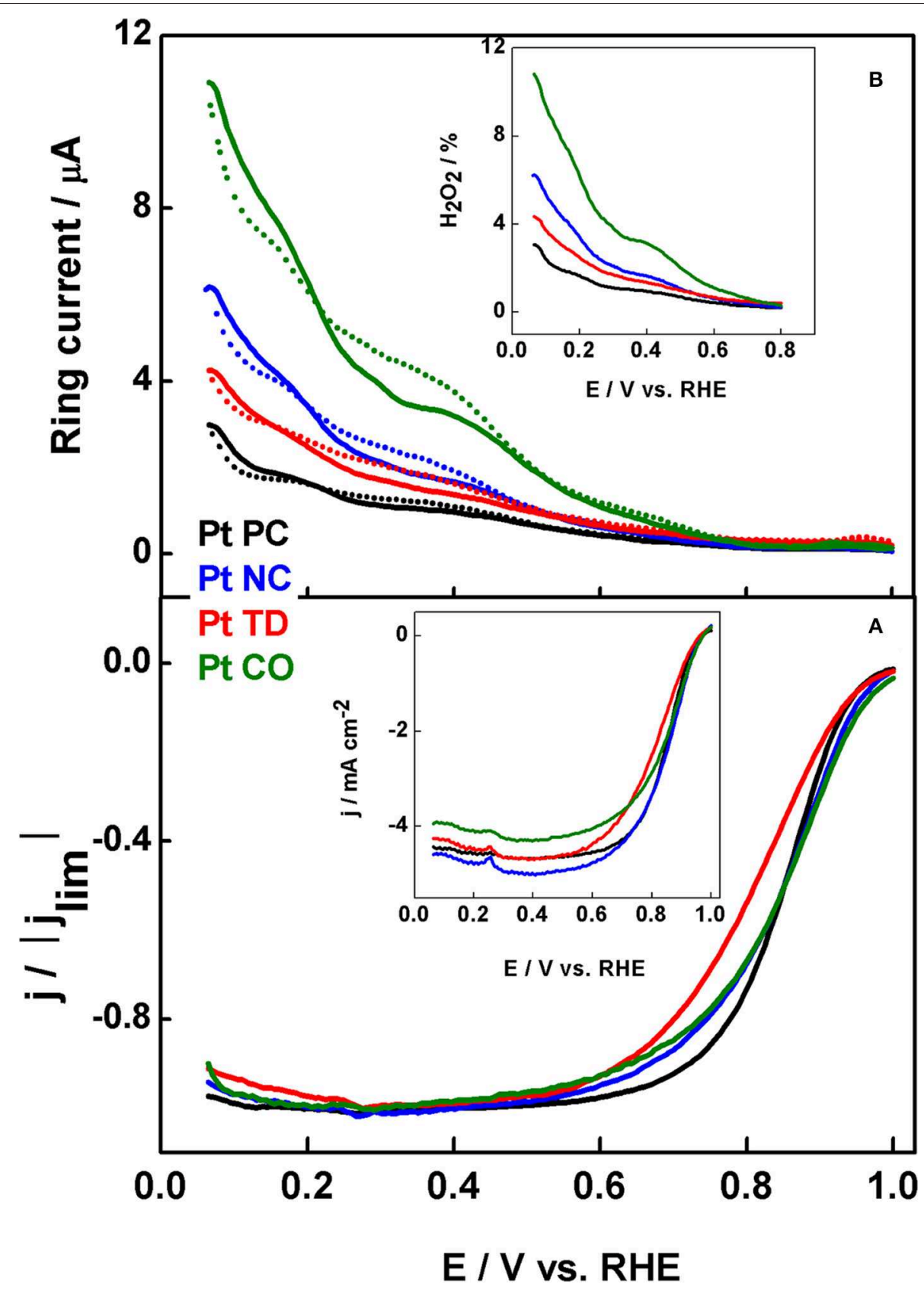

FIGURE 6 | (A) ORR voltammograms of Pt-PC, Pt-NC, Pt-TD and Pt-CO nanoparticles recorded in $\mathrm{O}_{2}$-saturated $0.5 \mathrm{M} \mathrm{H}_{2} \mathrm{SO}_{4}$ solution at $20 \mathrm{mV} \mathrm{s}^{-1}$ with 1,600 rpm. (B) $\mathrm{H}_{2} \mathrm{O}_{2}$ oxidation current obtained parallel to the ORR voltammograms; inset to (B) shows the fraction of $\mathrm{H}_{2} \mathrm{O}_{2}$ formation during $\mathrm{O}_{2}$ reduction. Reproduced with permission (Devivaraprasad et al., 2014). Copyright 2014, American Chemical Society (ACS).

the bulk of the sample. It also offers the surface atomic arrangement of a specific shape-controlled nanoparticle, which can vary significantly from one particle to another. When the characterization is limited to individual nanoparticles or a selected few particles, the derived conclusions can be obscured and it may not be representative of the average surface structure of the sample. In this case, it is important to analyze a large number of particles to obtain a statistically correct information on the surface. In other words, the available exsitu experimental techniques for the surface characterization of shape-controlled Pt nanoparticles do not emulate the practical electrochemical conditions.

Devivaraprasad et al. (2014) compared the ORR activities and peroxide formation of shape-controlled nanoparticles in acidic and alkaline electrolytes. Figure 6 shows ORR polarization curves of Pt-NC, Pt-CO, and Pt-TD in comparison with that of 
Pt-PC. In $0.5 \mathrm{M} \mathrm{H}_{2} \mathrm{SO}_{4}$ electrolyte, the activity order is Pt-NC $>\mathrm{Pt}-\mathrm{CO} \approx \mathrm{Pt}-\mathrm{PC}>\mathrm{Pt}-\mathrm{TD}$ and that in $0.1 \mathrm{M} \mathrm{HClO}_{4}$ is $\mathrm{Pt}-\mathrm{TD}$ $>$ Pt-PC $>$ Pt-NC $>$ Pt-CO. On the other hand, the order of peroxide formation order is $\mathrm{Pt}-\mathrm{CO}>\mathrm{Pt}-\mathrm{NC}>\mathrm{Pt}-\mathrm{TD}>\mathrm{Pt}-\mathrm{PC}$ and $\mathrm{Pt}-\mathrm{CO}>\mathrm{Pt}-\mathrm{NC}>\mathrm{Pt}-\mathrm{TD} \approx \mathrm{Pt}-\mathrm{PC}$ in $0.5 \mathrm{M} \mathrm{H}_{2} \mathrm{SO}_{4}$ and $0.1 \mathrm{M} \mathrm{HClO}_{4}$, respectively. At the same time, the activity and peroxide formation trends in $0.1 \mathrm{M} \mathrm{NaOH}$ are entirely different. The trends observed are correlated with that of single crystal electrodes reported in the literature. The change in order of ORR activity in the above-mentioned electrolytes is explained on the basis of specific adsorption of anions available on $\{111\} /\{100\}$ terrace sites. It is also noticed that the peroxide formation (5$12 \%$ ) is higher in $0.5 \mathrm{M} \mathrm{H}_{2} \mathrm{SO}_{4}$ and $\mathrm{NaOH}$ (strongly adsorbing electrolyte) as compared to that in $0.1 \mathrm{M} \mathrm{HClO}_{4}$ (1.5-5\%), a weakly adsorbing electrolyte. The variations in the trend of peroxide formation originate from the overlap of ORR with $\mathrm{H}_{\text {upd }}$ at lower potentials, which inhibits the adsorption of oxygen for reduction. Moreover, there is a particle size effect, wherein a decrease in re-adsorption and reduction of peroxide is observed with increase in particle size of Pt (Devivaraprasad et al., 2014). Sanchez-Sanchez et al. (2010) used the tip generationsubstrate collection (TG-SC) mode of scanning electrochemical microscopy and presented the direct observation of different catalytic sites for four shape-controlled Pt NPs catalyzing ORR in two different acid electrolytes $\left(0.1 \mathrm{M} \mathrm{HClO}_{4}\right.$ and $\left.0.5 \mathrm{M} \mathrm{H}_{2} \mathrm{SO}_{4}\right)$.

All these studies demonstrate surface structure dependence of ORR. Moreover, they have been able to correlate the results from imaging of shape-controlled nanoparticles and their catalytic activity with that of well-defined single crystal surfaces. These results underline the importance of shape, size and surface structure of nanoparticles in electrocatalysis; moreover, electrocatalytic activity depends strongly on the electrolyte employed for the investigation. Thus, it is important to recall that shape is a necessary prerequisite to define a particular type of surface structure but it is not a sufficient condition; or, shape is an indication of the surface structure. Thus, surface structure and shape are not the same, although they could be correlated, and it is important to differentiate between shape and surface structure at an atomic level.

\section{Case of Palladium}

Investigations on single crystal surfaces of Pd demonstrate that, at $0.9 \mathrm{~V}$ (RHE), the specific activity of Pd (100) toward ORR is three times higher compared to that of Pt (110). Moreover, the ORR activity of Pd single crystal surfaces (Figure 7) is in the order of $\mathrm{Pd}(110)<\mathrm{Pd}(111)<\mathrm{Pd}(100)$, opposite to that with respective Pt surfaces in $0.1 \mathrm{M} \mathrm{HClO}_{4}$ solution (Kondo et al., 2009). The DFT studies suggest that the order of adsorption energy between $\mathrm{O}$ adatom and Pd facets is O-Pd (100) > O-Pd (111) > O-Pd (110) and thus the weak interaction between $\mathrm{O}$ adatom and $\mathrm{Pd}$ (110) facet is proposed to be the reason for the observed lower activity (Xiao et al., 2009).

Investigation using $\mathrm{X}$-ray scattering were conducted to understand the surface of Pd single crystal under electrochemical conditions and to find active site for ORR. It was reported that there is substantial expansion in the inter layer spacing $(5.3 \%)$ between $d_{12}$ and $d_{23}\left(d_{12}\right.$ and $d_{23}$; first and second, second

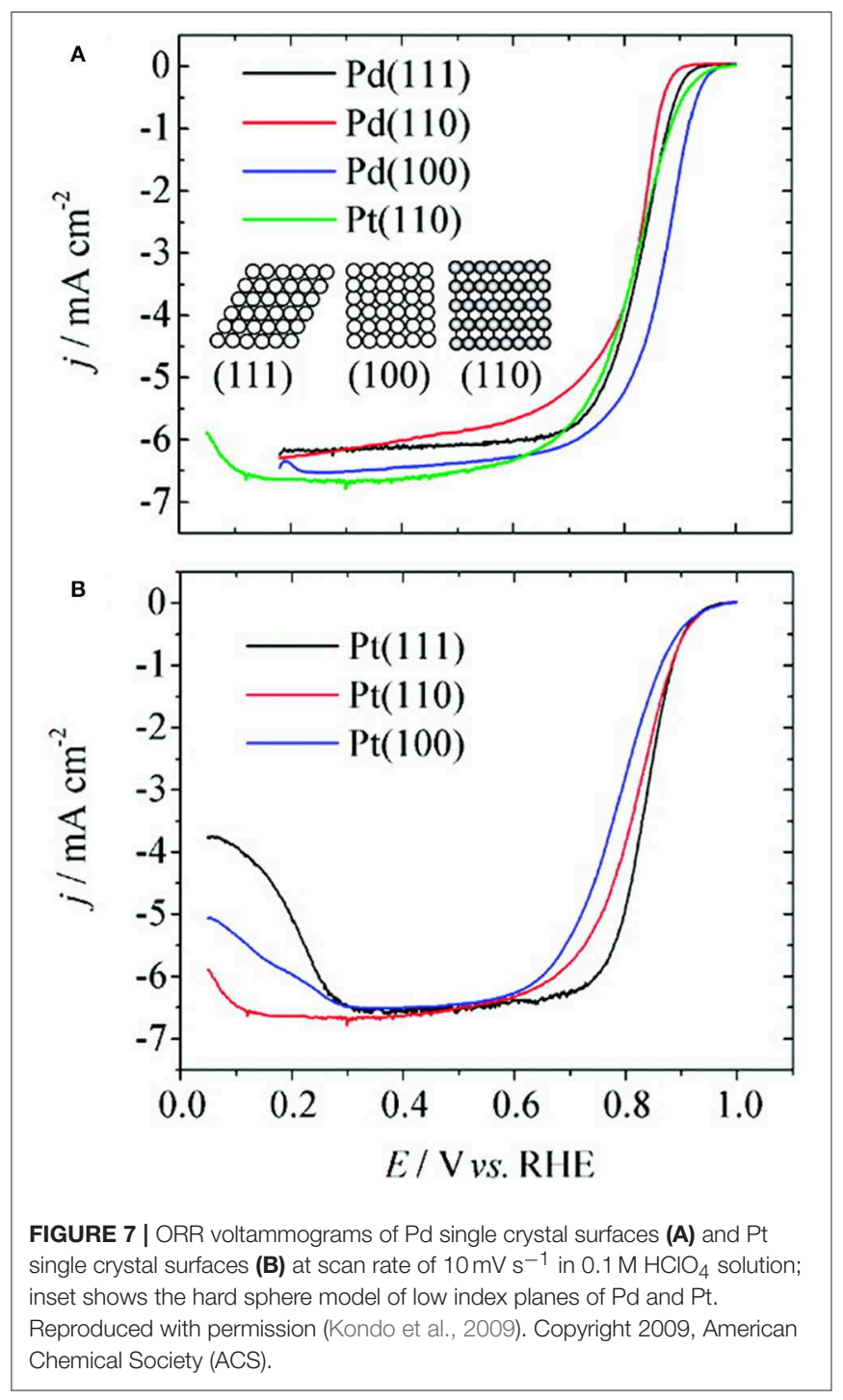

and third, respectively) on Pd (100) surfaces while it is only $1.8 \%$ on $\mathrm{Pd}(111)$ surfaces in oxygen-saturated solution of $0.1 \mathrm{M}$ $\mathrm{HClO}_{4}$. Therefore, the high degree of expansion with Pd (100) compared to $\mathrm{Pd}$ (111) may correspond to stronger interaction of oxygen with Pd (100) and hence leads to high activity (Naito et al., 2011). The ORR voltammograms over carbon-supported shape-controlled Pd nanoparticles suggest that there is 10 -fold of higher ORR activity with $\mathrm{Pd}$ nanocubes compared to that of $\mathrm{Pd}$ octahedral in $0.1 \mathrm{M} \mathrm{HClO}_{4}$ solution. The in-situ production of oxygen-containing species $\left(\mathrm{O}_{2}, \mathrm{O}, \mathrm{OH}\right.$, and $\left.\mathrm{OOH}\right)$ and their unique interaction with $\mathrm{Pd}$ facets were proposed to be the reason for structural dependence of Pd for ORR (Shao, 2011; Shao et al., 2011 , 2013). Besides, in strongly adsorbing electrolytes $(0.5 \mathrm{M}$ $\mathrm{H}_{2} \mathrm{SO}_{4}$ ), the same trend in activity (that is higher activity with Pd NC compared to Pd octahedral) was observed; however, there is overall decrease in activity because of strong adsorption of bi(sulfate) anions on the catalyst surface. It was reported that the symmetry between $\mathrm{Pd}$ (111) facets and oxygen atoms in 
bi(sulfate) anions may drastically lower the ORR activity by significantly hindering the adsorption of $\mathrm{O}_{2}$ molecules. On the other hand, there was no such facet dependent ORR activity with shape dependent $\mathrm{Pd}$ nanoparticles in $0.1 \mathrm{M} \mathrm{NaOH}$ solution; all the nanoparticles showed similar activities. This result is different from that of the previous reports of high activity with Pd NC as compared to spherical and cubooctahedral Pd nanoparticles.

The electrochemical characteristics of $\mathrm{Pd}$ surface after cleaning with $\mathrm{NaBH}_{4}$ is shown in Figure 8. Clean precious metal Pd CV features, $\mathrm{H}_{\text {upd }}(0-0.35 \mathrm{~V})$, double layer $(0.35-0.7 \mathrm{~V})$ and metal oxidation/reduction $(0.7-1.05 \mathrm{~V})$ regions were observed from Figure 8A. The ORR voltammograms in Figure 8B of cleaned shape-controlled $\mathrm{Pd}$ nanoparticles suggested that $\mathrm{Pd}$ NC dominant with (100) facets was more active compared to Pd octahedral dominant with (111) facets; these results were in line with that of Pd single crystal surfaces and other reports those were established on shape-controlled Pd nanoparticles. Therefore, this study established a cleaning method based on Pd hydride formation, which can remove the impurities without disturbing the structural integrity of shape-controlled Pd nanoparticles (Nalajala et al., 2016).

Erikson et al. (2016) carried out a comprehensive investigation with carbon-supported Pd-NCs of different sizes $(\sim 7, \sim 10$, $\sim 30 \mathrm{~nm}$ ) and loading from 20 to $50 \mathrm{wt} \%$ for ORR in acidic solutions $\left(0.1 \mathrm{M} \mathrm{HClO}_{4}\right.$ and $\left.0.5 \mathrm{M} \mathrm{H}_{2} \mathrm{SO}_{4}\right)$. The ORR activity results suggested that the specific activity of $\mathrm{Pd}-\mathrm{PC}$ dominant with all facets is lower compared to that of Pd-NCs dominant with (100) facets, but decreases with decrease in size of the nanocube. Whereas, the mass activity of $\mathrm{Pd}-\mathrm{NC}$ increases with decrease in size of the nanocube.

Figure 9 demonstrates the copper stripping voltammograms and their corresponding background voltammograms (inset to Figure 9A). Conventionally, the surface area is measured from the charge associated with $\mathrm{CO}$ stripping voltammetry and $\mathrm{H}_{\text {upd }}$ region of the voltammogram. In this context, the under potential deposition of metal adatoms (for e.g., $\mathrm{Cu}$ ) above their reversible potential on foreign metal substrates/surfaces is employed in order to explore the surface area of catalyst materials. Due to distinct adsorption energies of $\mathrm{Cu}$, it is also possible to probe and identify the dominant crystallographic facets, which are present on the surface of catalyst (Pronkin et al., 2007). The appearance of peaks at different potentials may be correlated to the binding energies between the adatoms (for e.g., $\mathrm{Cu}$ ) and the atoms of the substrate/surface. Moreover, using the $\mathrm{Cu}$ stripping method, one can explore the surface composition of the electrocatalyst. The facet dominance of Pd nanoparticles are clearly evident from the $\mathrm{Cu}$ stripping voltammograms; intense peaks observed at $0.41 \mathrm{~V}$ and $0.56 \mathrm{~V}$ were assigned to (100) facets of Pd NC samples those were prepared by both $\mathrm{KCl}$ and $\mathrm{KBr}$ as capping agents. Besides, the intense peak at $0.51 \mathrm{~V}$, corresponding to (111) facet, was quite dominant with truncated octahedral and MTP shapes of Pd. The ORR voltammograms (Figure 9B) of these samples recorded in $\mathrm{O}_{2}$-saturated $0.1 \mathrm{M} \mathrm{HClO}_{4}$ solution suggested that the trend in half-wave potentials is in accordance to the activity that was reported on Pd single crystal surfaces; (100) facet is more active compared to (111) facet. At the same time, features of Pd were not observed for the nanoparticles synthesized with $\mathrm{I}^{-}$ ion as capping agent, demonstrating that $\mathrm{NaBH}_{4}$ could not clean adsorbed $\mathrm{I}^{-}$impurities; thus, one cannot observe electrocatalytic activity for ORR.

According to Sabatier's principle, there should be an optimum binding between reactants, intermediates, products and metal surface for efficient catalytic and electrocatalytic reactions. In this context, recently, Wang et al. (2019) proposed a general and powerful strategy that provides the tuning of intrinsic surface strain in the metal nanosheets for electrocatalytic properties; for instance, ORR in alkaline and acid solutions. They found that the specific activity (SA) in $0.1 \mathrm{M} \mathrm{HClO}_{4}$ at $0.95 \mathrm{~V}$ for 3-ML, 5 ML, 8-ML was $10,14,5$ times, while in $0.1 \mathrm{M} \mathrm{KOH}$ was 15,18 , and 2 times higher than that of $\mathrm{Pd}$ nanoparticles, respectively. Through DFT studies, they established a relationship between thickness of the slab and compressive strain that causes ORR activity. It is found that $0.35,0.92$, and $2.50 \%$ compressive strain was obtained for 8-ML, 5-ML, and 3-ML, respectively. In general, the unstrained surface binds oxygen very strongly, which limits the ORR by slow oxidative desorption of hydroxides. On the other hand, with decreasing slab thickness, providing more compressive stains enables weak binding of $\mathrm{O}^{*}$ and thus provide better ORR kinetics. Therefore, in accordance with Sabatier's principle, the optimum thickness of slab (5-ML) would be able to exhibit much better ORR activities in both alkaline and acidic solutions. In the literature it is reported that $\mathrm{PdH}_{0}$ nanocubes can exhibit comparable activity as that of commercial $\mathrm{Pt} / \mathrm{C}$. Moreover, $\mathrm{PdH}_{0.7}$ exhibits mass activity $\sim 3.75$ times better than that of $\mathrm{PdH}_{0}$ (Lu et al., 2017).

Literature is replete with shape-dependent ORR in acidic solutions $\left(\mathrm{HClO}_{4}, \mathrm{H}_{2} \mathrm{SO}_{4}\right)$ and alkaline solutions $(\mathrm{NaOH}, \mathrm{KOH})$ for fuel cell applications. ORR in ionic liquids (ILs) is of technological and scientific importance in lithium-air/lithiumoxygen batteries. For instance, rechargeable lithium-air batteries provide 3-5 times better gravimetric energy density compared to conventional Li-ion batteries. However, poor electrolyte stability in the presence of ORR intermediates, such as superoxide anion radicals $\left(\mathrm{O}_{2}^{*}\right)$, is one of the major challenges in the development of $\mathrm{Li}-\mathrm{air} / \mathrm{Li}-\mathrm{O}_{2}$ batteries. Therefore, studies on ORR in ILs using different metal surfaces and nanoparticles received significant attention recently (Laoire et al., 2010; Ernst et al., 2011). In general, electrolytes based on ILs are promising because of their low volatility, low toxicity, high ionic conductivity, thermal, chemical and electrochemical stability (Schwenke et al., 2015). In this context, Evans et al. (2004) pursued a comprehensive investigation over electrogeneration of stable superoxide ions at different material surfaces such as platinum, gold, and glassy carbon electrode in various room temperature quaternary ammonium ILs and quaternary phosphonium ILs. Lu et al. (2011) carried out remarkable studies on polycrystalline $\mathrm{Pd}, \mathrm{Au}, \mathrm{Pt}, \mathrm{Ru}$, and glassy-carbon via rotating disk electrodes ( $\mathrm{RDE}$ ) measurements in non-aqueous $0.1 \mathrm{M} \mathrm{LiClO}_{4}$ in 1,2-dimethoxyethane electrolyte and found that the volcano type $\mathrm{Li}^{+}$-ORR activity is in the order of $\mathrm{Pd}>$ $\mathrm{Pt}>\mathrm{Ru} \approx \mathrm{Au}>\mathrm{GC}$. Moreover, it is established that the obtained ORR activity trend is in good agreement with the discharge voltage of $\mathrm{Li}-\mathrm{O}_{2}$ cells those were made of nanoparticle catalysts (Lu et al., 2011). Recently, the shape-dependent 

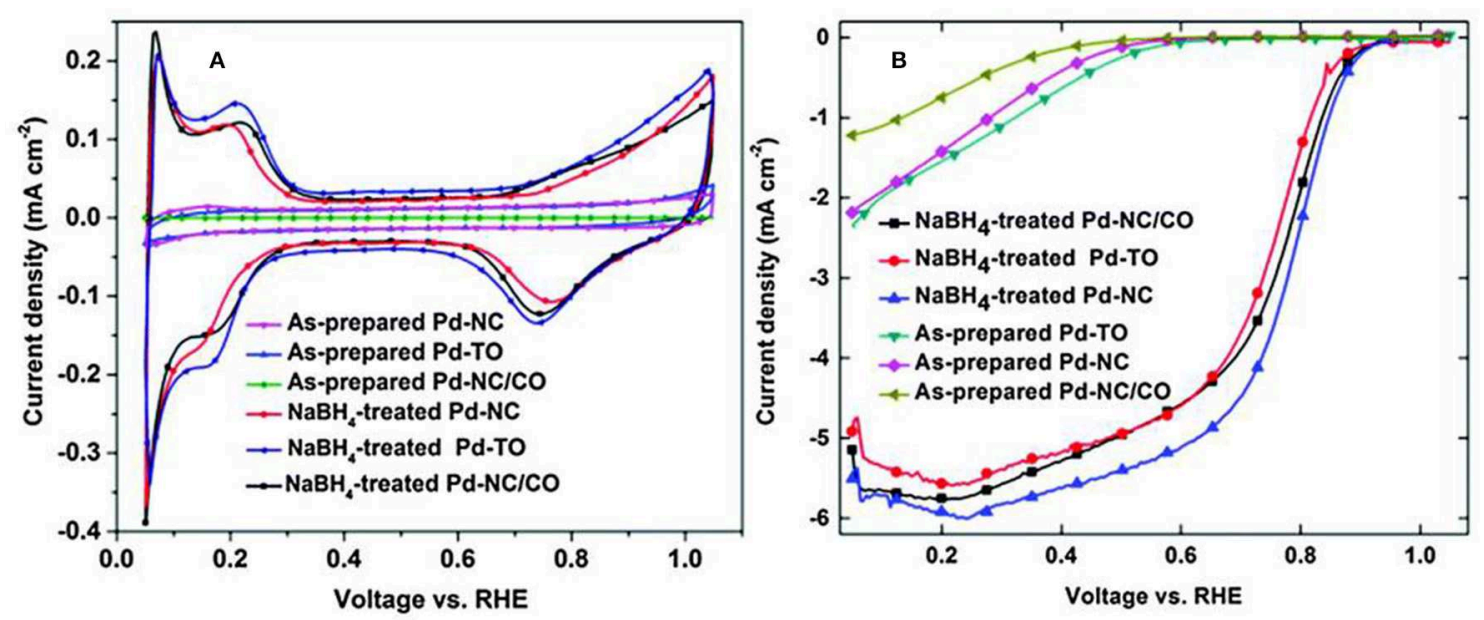

FIGURE 8 | (A) CVs, (B) ORR voltammograms of shape-controlled Pd nanoparticles (as prepared and that subjected to $\mathrm{NaBH}_{4}$ treatment) recorded in $0.1 \mathrm{M} \mathrm{HClO}_{4}$ at a scan rate of $20 \mathrm{mV} \mathrm{s}^{-1}$. Reproduced with permission (Nalajala et al., 2014). Copyright 2014, Royal Society of Chemistry (RSC).

ORR activity of $\mathrm{Pd}$ in IL, 1-butyl-1-methylpyrrolidinium bis(trifluoromethylsulfonyl)imide ([Bmpy][NTf2]), was reported (Tang et al., 2016). The prepared nanoparticles were immobilized on gas permeable membrane for measuring the ORR activity in the afore-mentioned ionic liquid. It was observed that rhombic dodecahedral Pd nanoparticles dominant with high energy facet (110) possess better catalytic activity for oxygen reduction compared to that of cubic Pd with dominant (100) facets (Tang et al., 2016). The literature on shape-dependent ORR in ILs is very limited and more efforts are required to understand the facetdependent ORR kinetics in ILs (Girishkumar et al., 2010; Wang et al., 2014).

\section{STABILITY OF METAL NANOPARTICLES UNDER ELECTROCHEMICAL CONDITIONS}

Various researchers investigated stability of Pt single crystal electrodes during the potential cycling in the electrochemical environment. Thus, Clavilier and Armand (1986) established the dissolution rates over a range of potentials (Yamamoto et al., 1979; Clavilier and Armand, 1986; Marković et al., 1988, 1991; Wagner and Ross, 1988; Rodes et al., 1990; Kolb, 1995). It was concluded that the rate of dissolution is slow in the potential range of 0.06 to $0.8 \mathrm{~V}$ with any given Pt surface and it is unlikely to occur.

In case of $\mathrm{Pt}(111)$ surface, the so-called characteristic "butterfly features" observed in the potential range of 0.4$0.6 \mathrm{~V}$ in acidic electrolyte and other typical Pt features observed in alkaline electrolyte remains undisturbed, only if the upper potential limit is restricted to $\leq 0.8 \mathrm{~V}$. These features of the reversible adsorption of hydrogen and anions in the $\mathrm{H}_{\text {upd }}$ region correspond to well-ordered (111) terrace sites (Kolb, 1995). In case of $\mathrm{Pt}(100)$ surface, significant changes in the voltammetric features were noticed even with potential cycling in the lower ranges. Thus, the stability of (100) surfaces is inferior to that of (111) surfaces (Clavilier and Armand, 1986; Wagner and Ross, 1988; Kolb, 1995). Investigations on single crystal surfaces ( $\{100\} ;\{111\} ;\{110\})$, when subjected to potential cycling above $1.0 \mathrm{~V}$, offer evidence for dissolution and reconstruction and it is influenced by the adsorbates and temperature (Clavilier and Armand, 1986; Wagner and Ross, 1988; Kolb, 1995).

Lopes et al. (2016) developed a unique method that utilized a stationary probe coupled to Inductively Coupled Plasma Mass Spectrometry (ICP-MS), combined with a rotating Pt(hkl)disk electrode (RDE), to study the role of surface geometry on the stability of surface atoms. It enabled "atom-by-atom" detection of the adsorbate-induced dissolution of $\mathrm{Pt}$ in acidic and alkaline environments. This study demonstrated that the structure-stability relationships established for platinum single crystals can be used as a foundation for understanding the stability of polycrystalline Pt electrodes and Pt nanoparticles. It was shown that the overall dissolution rates were driven by a synergy between electrochemical (potential induced oxide formation) and chemical corrosion (thermodynamic driving force for $\mathrm{Pt}$ complexation). It was also shown that the dissolution dynamics were strongly affected by the nature of the electrochemical reaction; thus, continuous dissolution occurs during the oxygen evolution reaction (OER), limited dissolution during $\mathrm{CO}$ oxidation reaction, and no dissolution during the ORR. Reconstruction and dissolution of Pt surface are evidenced by the new voltammetric features at specific potentials and by the presence of $\mathrm{Pt}^{2+}$ ions in the electrolyte, respectively. But, longterm electrochemical investigations on extended single crystal surfaces are limited.

With conventional polycrystalline nanoparticles, all the lowindex crystallographic orientations feature on the surface (no preferential dominance); therefore, investigating the extent of reconstruction and dissolution is a daunting task. Nevertheless, the reconstruction of nanoparticles is investigated using high pressure scanning tunneling microscopy (HP-STM), ambient 

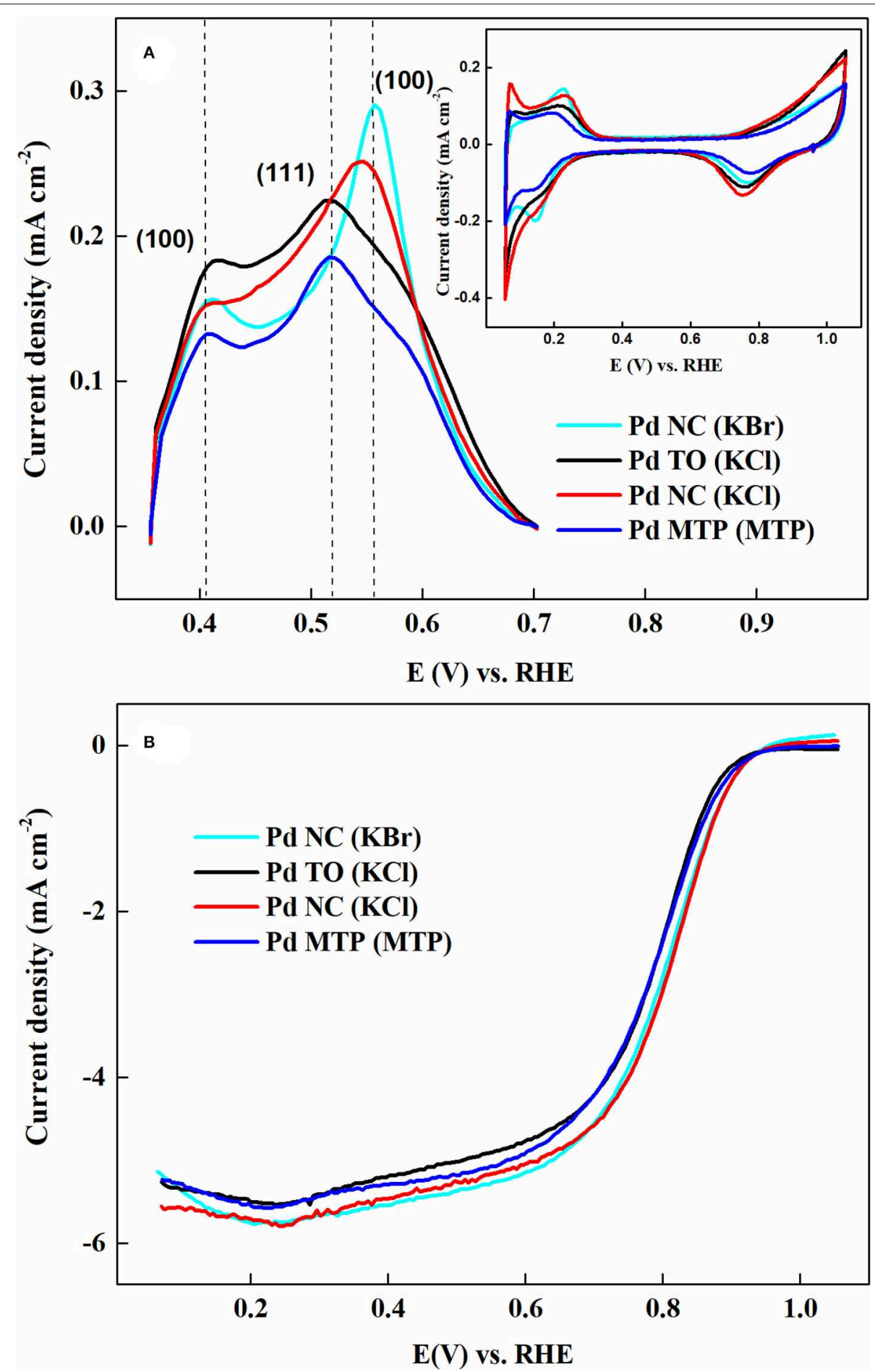

FIGURE 9 | (A) Cu stripping voltammograms of shape-controlled Pd nanoparticles recorded at scan rate of $10 \mathrm{mV} \mathrm{s}^{-1}$ in an Ar-saturated $0.1 \mathrm{M} \mathrm{HCIO}_{4}$ contained

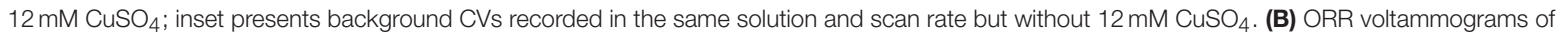
shape-controlled Pd nanoparticles recorded at scan rate of $20 \mathrm{mV} \mathrm{s}^{-1}$ with $1,600 \mathrm{rpm}$ in $\mathrm{O}_{2}$-saturated $0.1 \mathrm{M} \mathrm{HClO}_{4}$ solution. Reproduced and modified with permission (Nalajala et al., 2016). Copyright 2016, Institute of Physics (IOP).

pressure X-ray photoelectron spectroscopy (AP-XPS), in situ XRD, and TEM (Arenz et al., 2003; Garcia-Araez et al., 2005). With the change in temperature, pressure and potential, metal nanoparticles are susceptible to surface structural changes. The stability of $\mathrm{Pt}$ nanoparticles is also affected by $\mathrm{pH}$, potential and presence of adsorbates (Kinoshita et al., 1973; Komanicky 


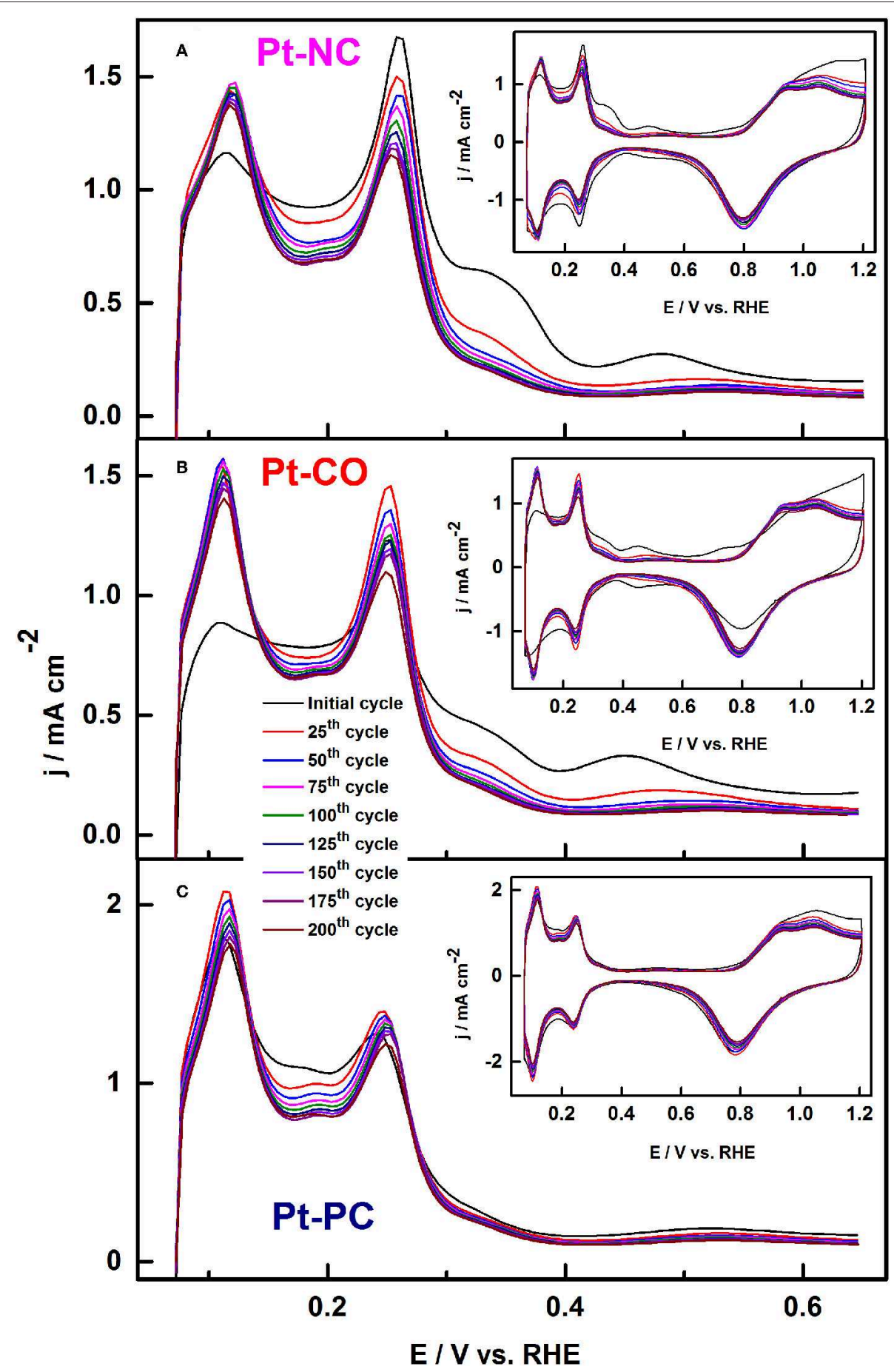

FIGURE 10 | Potential cycling of (A) Pt-NC, (B) Pt-CO, and (C) Pt-PC nanoparticles upto $1.2 \mathrm{~V}$ in argon-saturated $0.5 \mathrm{M} \mathrm{H}_{2} \mathrm{SO}_{4}$ electrolytes at a scan rate of $50 \mathrm{mV}$ $\mathrm{s}^{-1}$ (every 25th cycle upto 200 cycles). Inset shows the respective complete CVs up to 1.2 V. Reproduced with permission (Devivaraprasad et al., 2016). Copyright 2016, Royal Society of Chemistry (RSC).

et al., 2006; Wang et al., 2006; Yasuda et al., 2006; Tang et al., 2010a,b; Matsumoto et al., 2011; Sugawara et al., 2011, 2012; Kongkanand and Ziegelbauer, 2012; Topalov et al., 2012, 2014a,b; Ahluwalia et al., 2013; Xing et al., 2013; Cherevko et al., 2014; Arán-Ais et al., 2018). Unfortunately, conclusions derived from spectroscopic analytical tools and measurements carried out under ultra-high vacuum conditions (UHV) with single crystal surfaces cannot be directly implied with nanoparticle surfaces. At this juncture, work on shape-controlled $\mathrm{Pt}$ nanoparticles has, to some extent, bridged the gap between the single crystal 


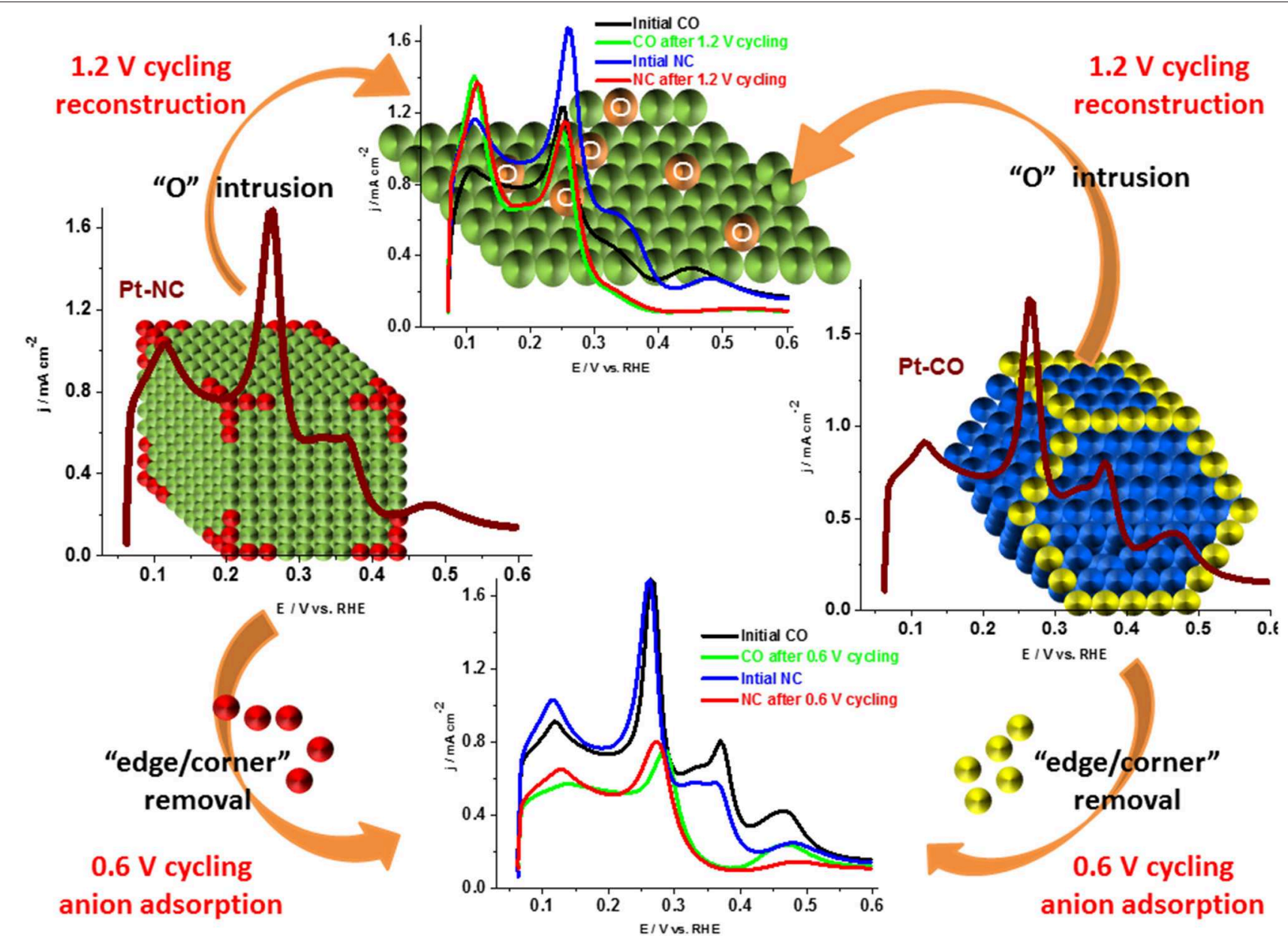

FIGURE 11 | Schematic showing Pt dissolution and reconstruction along with the corresponding voltammetric profiles in the Hupd region. Reproduced with permission (Devivaraprasad et al., 2016). Copyright 2016, Royal Society of Chemistry (RSC).

electrodes on one hand and Pt-based fuel cell electrocatalysts on the other hand.

Recently, Identical Location Transmission Electron Microscopy (IL-TEM) was used for the investigation of shape-controlled nanoparticles during electrochemical cycling, a process routinely followed in the activation of catalyst surface (Arán-Ais et al., 2015a). They reported significant changes in the shape and morphology of hexagonal nanoparticles and particle migration on potential cycling to $1.3 \mathrm{~V}$ (Arán-Ais et al., 2015b).

Similar results were reported recently by Devivaraprasad et al. (2016) and Arán-Ais et al. (2015b) in the investigation of stability and surface structure of clean shape-controlled nanoparticles in $0.5 \mathrm{H}_{2} \mathrm{SO}_{4}$ electrolyte. It was observed that Pt-NC and Pt-CO reconstruct to Pt-PC on potential excursion to 1.0 and $1.2 \mathrm{~V}$. Such changes to the shape of the nanoparticle is correlated with the rise in peak features at potential 0.125 and $0.27 \mathrm{~V}$ in the $\mathrm{H}_{\text {upd }}$ region originating from the $\{110\}$ sites and $\{100\}$ steps sites, at the expense of $\{100\}$ and $\{111\}$ terrace sites (Figure 10). Unlike expected, the reduction in $\mathrm{H}_{\text {upd }}$ area is negligible on potential excursion of the electrode to 1 and $1.2 \mathrm{~V}$. This is because of the protective oxide surface on Pt, which hinders further dissolution. When potential limit is restricted to 0.6 or $0.8 \mathrm{~V}$, there is a significant decrease in the $\mathrm{H}_{\mathrm{upd}}$ area of both Pt-PC and shape-controlled Pt nanoparticles as presented in Figure 11. Such reduction in $\mathrm{H}_{\text {upd }}$ area is due to adsorption and subsequent accumulation of electrolyte anions. The recovery of the $\mathrm{H}_{\text {upd }}$ charge on cycling to potential above $1 \mathrm{~V}$ supports the above-mentioned conclusion. Thus, the adsorbed anions were substituted with oxygenated species on $\mathrm{Pt}$, which subsequently gets reduced at lower potentials. Amongst different shapecontrolled Pt nanoparticles, Pt-NCs dissolved at a faster rate than Pt-CO or Pt-PC. The HRTEM images demonstrated the loss of $\{111\}$ and $\{100\}$ terraces and led to spherical particles of comparable size, conforming with the observation from the voltammograms (Devivaraprasad et al., 2016).

Some of these findings evidently shed light on various aspects of the stability of metal nanoparticles, and most importantly, emphasize the potential range to be considered in the investigation of shape-dependent electrochemical reactions. Thus, one has to be extremely careful while deriving conclusion 
in the investigations on shape-controlled nanoparticles, particularly with reactions involving high potentials, such as that with ORR. It is well-established in the literature that the stability of $\mathrm{Pd}$ nanoparticles is poorer than that of $\mathrm{Pt}$ nanoparticles, and the readers are suggested to refer previous references and discussion on such aspects is beyond the scope of this review (Meier et al., 2005; Wells et al., 2009; Singh et al., 2013; Mittermeier et al., 2015; Zadick et al., 2016).

\section{NON-RECOVERABLE ESA LOSSES WITH HALIDE ION ADSORPTION AND ACTIVE SURFACE RECOVERY METHODS OF SHAPE-CONTROLLED PT NANOPARTICLES}

The adsorption processes at platinum electrodes are known to complicate the kinetics of surface-sensitive electrochemical reactions. Thus, ORR was investigated at platinum electrode surfaces in the presence of various cations $\left(\mathrm{Na}^{+}, \mathrm{K}^{+}\right.$, etc.) (Okada et al., 1999; Durst et al., 2012), anions $\left(\mathrm{ClO}_{4}^{-}, \mathrm{HSO}_{4}^{-2}\right.$, etc.) (Hsueh et al., 1983), halides $\left(\mathrm{Cl}^{-}\right.$and $\mathrm{Br}^{-}$) (and Marković et al., 1999; Schmidt et al., 2001; Stamenkovic et al., 2001) and other impurities $\left(\mathrm{PO}_{4}^{3-}, \mathrm{NH}_{4}^{+}, \mathrm{CO}, \mathrm{SO}_{2}, \mathrm{H}_{2} \mathrm{~S}\right.$, etc.) (Macia et al., 2004; Stamenkovic et al., 2005; Halseid et al., 2008; He et al., 2010; Ong et al., 2013; Rahul et al., 2015; Briega-Martos et al., 2018). Therefore, strongly adsorbing anions/cations/impurities/in situ generated adsorbed species on the catalyst surface interfere with the investigation of dissolution and reconstruction of nanoparticles, making it is hard to investigate the stability, origin of the loss of ESA, and catalytic activity of nanoparticles.

Influence of halides ions adsorbed on single crystal electrodes of Pt was extensively reported by various groups (Solomun et al., 1984; Salaita et al., 1986; Shu and Bruckenstein, 1991; Vogel and Baltruschat, 1991; Oelgeklaus et al., 1994; Albers et al., 1995; DeSimone and Breen, 1995; Abruna et al., 1998; Arenz et al., 2003; Garcia-Araez et al., 2004, 2005, 2006a,b). AES/LEED investigations lead to the conclusion that the $\mathrm{Cl}^{-}$ ion adsorption occurs on $\mathrm{Pt}(100)$ and $\mathrm{Pt}$ (111) surfaces at two different potentials, i.e., in the $\mathrm{H}_{\text {upd }}$ and $\mathrm{OH}$ adsorption regions, respectively (Arruda et al., 2008). The Pt (100) surface was shown to be affected by $\mathrm{Cl}^{-}$adsorption at a lower potential than $\mathrm{Pt}$ (111) surface, suggesting higher vulnerability of the former to chloride ions (Arruda et al., 2008).

In the process of translating the understanding of fundamental studies carried out at single crystal surfaces to the nanoparticle surfaces, the effect of halide ions $\left(\mathrm{I}^{-}, \mathrm{Br}^{-}, \mathrm{Cl}^{-}\right)$on $\mathrm{H}_{\mathrm{ads} / \mathrm{des}}$ and reconstruction of shape-controlled Pt nanoparticles (Pt-NCs and Pt-COs) and Pt-PCs were investigated in $0.5 \mathrm{M}$ $\mathrm{H}_{2} \mathrm{SO}_{4}$ electrolyte (Devivaraprasad et al., 2017). Characteristic facet-dependent $\mathrm{I}^{-}, \mathrm{Br}^{-}, \mathrm{Cl}^{-}$adsorption/desorption features were observed and the adsorption strength of halides was in the order of $\mathrm{I}^{-}>\mathrm{Br}^{-}>\mathrm{Cl}^{-}$; thus, the $\mathrm{H}_{\text {upd }}$ area of $\mathrm{Pt}$ decreased significantly with the addition of $\mathrm{I}^{-}$ions to $0.5 \mathrm{M}$ $\mathrm{H}_{2} \mathrm{SO}_{4}$ electrolyte. With $\mathrm{Br}^{-}$and $\mathrm{Cl}^{-}$ions, $\mathrm{Pt}$ exhibited a concurrent $\mathrm{H}_{\text {ads/des }} / \mathrm{Br}_{\text {ads/des }}^{-} / \mathrm{Cl}_{\text {ads/des }}^{-}$features in the $\mathrm{H}_{\text {upd }}$

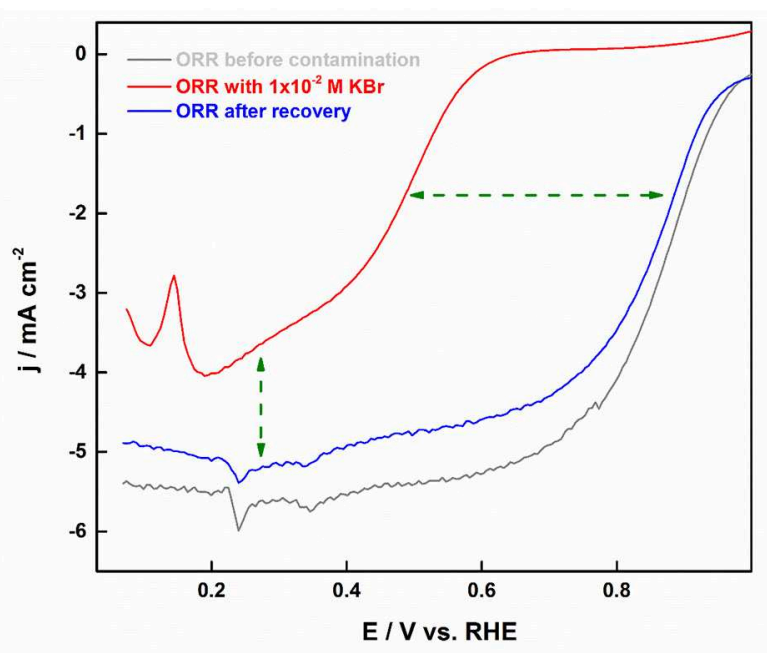

FIGURE 12 | ORR polarization curves with Pt-CO in oxygen-saturated $0.5 \mathrm{M}$ $\mathrm{H}_{2} \mathrm{SO}_{4}$ in relation to that intentionally contaminated with $10^{-3} \mathrm{M} \mathrm{Br}^{-}$ions. Reproduced with permission (Devivaraprasad et al., 2017). Copyright 2017, Journal of the Electrochemical Society (ECS).

region $(0.06-0.4 \mathrm{~V})$. As discussed in section Stability of Metal Nanoparticles Under Electrochemical Conditions on the effect of potential cycling in pure electrolytes, it is observed that the shape-controlled $\mathrm{Pt}$ nanoparticles undergo reconstruction in the presence of halide ions as well. Thus, potential cycling in the range of $0.06-1.4$ or $1.6 \mathrm{~V}$ causes the conversion of ordered terraces to disordered sites, resulting in eventual Pt-PC voltammetric features (Devivaraprasad et al., 2017).

An in situ potentiostatic method was devised for the removal of absorbed halide ions from the Pt surface, wherein the working electrode was immersed in $0.1 \mathrm{M} \mathrm{NaOH}$ solution at $\sim 0.03 \mathrm{~V}$. This method was proved to be effective enough to recover the active surface area without altering the facet-structure of shapecontrolled nanoparticles. Figure 12 shows an in-situ cleaning procedure employed in recovering the ORR activity.

Recently, Unnikrishnan et al. (2018), also reported the deleterious effects of $\mathrm{Cl}^{-}$ions on introducing to anode and cathode sides of a PEMFC. At an operating voltage of $0.6 \mathrm{~V}$ and due to the presence of bare minimum amount of $\mathrm{Cl}^{-}$ions (100 ppm) in the feed stream, a performance loss of $\sim 94 \%$ with the anode and $\sim 82 \%$ with the cathode were observed (Unnikrishnan et al., 2018). While operating at higher current densities, a significant loss can be avoided due to the recovery processes (removal of $\mathrm{Cl}^{-}$species adsorbed on the platinum surface) happening at the anode side with the help of protons and on the cathode side with help of the hydroxyl ions (Unnikrishnan et al., 2018).

Adsorption of anions (sulfates and halides) is well-known to poison the catalyst surface and to retard the catalytic activity. Adsorbed impurities negatively impact the performance of fuelcells, batteries and electrolyzers and the activity of a surface depends strongly on the structure and cleanliness of the surface. These finding have important implications in recovering the 
active catalyst surface contaminated with impurities. Also, some of the methods discussed here may be a stepping stone in the direction of making fuel cells with long-term durability and sustained catalytic activity.

\section{CONCLUSIONS AND FUTURE PROSPECT}

Investigations on well-defined single crystal electrode surfaces have established the facet dependence of various electrochemical reactions on precious metal surfaces ( $\mathrm{Pt}$ and $\mathrm{Pd})$. The adsorption free-energy on various facets decides the electrochemical activity. In an attempt to take advantage of the facet dependence of electrochemical reactions, various shape-controlled nanoparticles were synthesized using surfactants/capping agents/stabilizers etc. But, after the synthesis, it is essential to remove the surfactants from the surface of shape-controlled metal nanoparticles for enhanced electrocatalytic activityindeed a daunting task. Although various cleaning protocols have been proposed and proved to be efficient, it is important to understand that, most of these cleaning procedures are specific to the removal of individual surfactants or stabilizer or synthesis protocol employed and therefore the search for universal surfactant removal procedure is still underway.

Moreover, the facet dependent ORR activity of shapecontrolled nanoparticles is not as distinctive as that expected

\section{REFERENCES}

Abruna, H. D., Feliu, J. M., Brock, J. D., Buller, L. J., Herrero, E., Li, J., et al. (1998). Anion and electrode surface structure effects on the deposition of metal monolayers: electrochemical and time-resolved surface diffraction studies. Electrochim. Acta 43, 2899-2909. doi: 10.1016/S0013-4686(98)0 0030-9

Ahluwalia, R. K., Arisetty, S., Wang, X., Wang, X., Subbaraman, R., Ball, S. C., et al. (2013). The impact of dissolved reactive gases on platinum dissolution in acidic media. J. Electrochem. Soc. 160, F447-F455. doi: 10.1016/j.elecom.2013.12.021

Ahmadi, T. S., Wang, Z. L., Green, T. C., Henglein, A., and El-Sayed, M. A. (1996). Shape-controlled synthesis of colloidal platinum nanoparticles. Science 272, 1924-1926. doi: 10.1126/science.272.5270.1924

Albers, J., Baltruschat, and, H., and Kamphausen, I. (1995). On the structure of the $\mathrm{Pt}(100)$ and $\mathrm{Pt}(110)$ electrode surface in iodide solutions. J. Electroanal. Chem. 395, 99-105. doi: 10.1016/0022-0728(95)04063-T

Aliaga, C., Park, J. Y., Yamada, Y., Lee, H. S., Tsung, C.-K., Yang, P., et al. (2009). Sum frequency generation and catalytic reaction studies of the removal of organic capping agents from Pt nanoparticles by UV-Ozone treatment. J. Phys. Chem. C. 113, 6150-6155. doi: 10.1021/jp8108946

Antolini, E. (2009). Palladium in fuel cell catalysis. Ener. Environ. Sci. 2, 915-931. doi: 10.1039/B820837A

Arán-Ais, R. M., Solla-Gullón, J., Gocyla, M., Heggen, M., Dunin-Borkowski, R. E., Strasser, P., et al. (2016). The effect of interfacial pH on the surface atomic elemental distribution and on the catalytic reactivity of shape-selected bimetallic nanoparticles towards oxygen reduction. Nano Energy 27, 390-401. doi: 10.1016/ j.nanoen.2016.07.024

Arán-Ais, R. M., Solla-Gullón, J., Herrero, E., and Feliu, J. M. (2018). On the quality and stability of preferentially oriented (100) Pt nanoparticles: an electrochemical insight. J. Electroanal. Chem. 808, 433-438. doi: 10.1016/j.jelechem.2017.06.015

Arán-Ais, R. M., Vidal-Iglesias, F. J., Solla-Gullón, J., Herrero, E., and Feliu, J. M. (2015a). Electrochemical characterization of clean shape-controlled pt nanoparticles prepared in presence of oleylamine/oleic acid. Electroanalysis 27, 945-956. doi: 10.1002/elan.201400619 from that of single crystal surfaces. This is due to the exposure of a mix of almost all the low index crystallographic orientations on the nanoparticle surface along with surface defects, steps, kinks, edges and corners. However, methods based on $\mathrm{Bi}$ and $\mathrm{Ge}$ adsorption do provide means to estimate fraction of low-index sites and compare their ORR activities with that of well-defined surfaces; more work needs to be done in this area for estimation of contributions from other facets of shape-controlled nanoparticles. But this whole exercise has led to more information on long-term performance issues of polycrystalline Pt. Investigations on shape-controlled nanoparticles not only bridge the gap between fundamental studies and practical electrocatalysts employed, but also provide significant information on reconstruction, dissolution, specific adsorption of anions on the particle surfaces and recovery of electrocatalytic activity. Perhaps, nanoparticles with high-index sites stable under the fuel cell relevant potentials would be an ideal solution for high ORR activity. Designing such highly active and stable electrocatalysts, devoid of impurities, is still a work in progress.

\section{AUTHOR CONTRIBUTIONS}

All authors listed have made a substantial, direct and intellectual contribution to the work, and approved it for publication.
Arán-Ais, R. M., Yu, Y., Hovden, R., Solla-Gullón, J., Herrero, E., Feliu, J. M., et al. (2015b). Identical location transmission electron microscopy imaging of siteselective Pt nanocatalysts: electrochemical activation and surface disordering. J. Am. Chem. Soc. 137, 14992-14998. doi: 10.1021/jacs.5b09553

Arenz, M., Stamenkovic, V., Schmidt, T. J., Wandelt, K., Ross, P. N., and Marković, N. M. (2003). The effect of specific chloride adsorption on the electrochemical behavior of ultrathin Pd films deposited on Pt(111) in acid solution. Surf. Sci. 523, 199-209. doi: 10.1016/S0039-6028(02)02456-1

Arruda, T. M., Shyam, B., Ziegelbauer, J. M., Mukerjee, S., and Ramaker, D. E. (2008). Investigation into the competitive and site-specific nature of anion adsorption on Pt using in situ X-ray absorption spectroscopy. J. Phys. Chem. C 112, 18087-18097. doi: 10.1021/jp8067359

Bi, W., Gray, G. E., and Fuller, T. F. (2007). PEM fuel cell Pt / C dissolution and deposition in nafion electrolyte. J. Electrochem. Solid-State Lett. 10, B101-B104. doi: $10.1149 / 1.2712796$

Bisson, L., Boissiere, C., Nicole, L., Grosso, D., Jolivet, J. P., Thomazeau, C., et al. (2009). Formation of palladium nanostructures in a seed-mediated synthesis through an oriented-attachment-directed aggregation. Chem. Mater. 21, 2668-2678. doi: 10.1021/cm803421v

Briega-Martos, V., Mello, G. A. B., Arán-Ais, R. M., Climent, V., Herrero, E., and Feliu, J. M. (2018). Understandings on the inhibition of oxygen reduction reaction by bromide adsorption on $\mathrm{Pt}(111)$ electrodes at different $\mathrm{pH}$ values. $J$. Electrochem. Soc.165, J3045-J3051. doi: 10.1149/2.0081815jes

Burda, C., Chen, X., Narayanan, R., and El-Sayed, M. A. (2005). Chemistry and properties of nanocrystals of different shapes. Chem. Rev. 105, 1025-1102. doi: $10.1021 / \mathrm{cr} 030063 \mathrm{a}$

Chen, M., Wu, B., Yang, J., and Zheng, N. (2012). Small adsorbate-assisted shape control of Pd and Pt nanocrystals. Adv. Mater. 24, 862-879. doi: 10.1002/adma.201104145

Chen,. J., Lim, B., Lee, E. P., and Xia, Y. (2009). Shape-controlled synthesis of platinum nanocrystals for catalytic and electrocatalytic applications. Nano Today 4, 81-95. doi: 10.1016/j.nantod.2008.09.002

Cherevko, S., Zeradjanin, A. R., Keeley, G. P., and Mayrhofer, K. J. J. (2014). A comparative study on gold and platinum dissolution in acidic and alkaline media. J. Electrochem. Soc. 161, H822-H830. doi: 10.1149/2.0881412jes 
Chun-Jiang, J., and Schuth, F. (2011). Colloidal metal nanoparticles as a component of designed catalyst. Phys. Chem. Chem. Phys. 13, 2457-2487. doi: $10.1039 / \mathrm{C} 0 \mathrm{CP} 02680 \mathrm{H}$

Clavilier, J., and Armand, D. (1986). Electrochemical induction of changes in the distribution of the hydrogen adsorption states on Pt (100) and Pt (111) surfaces in contact with sulphuric acid solution. J. Electroannl. Chem. 199, 187-199. doi: 10.1016/0022-0728(86)87051-6

Clavilier, J., Feliu, J. M., and Aldaz, A. (1988). An irreversible structure sensitive adsorption step in bismuth under potential deposition at platinum electrodes. J. Electroanal. Chem. 243, 419-433. doi: 10.1016/0022-0728(88)80045-7

Collins, G., Davitt, F., O’Dwyer, C., and Holmes, J. D. (2018). Comparing thermal and chemical removal of nanoparticle stabilizing ligands: effect on catalytic activity and stability. ACS Appl. Nano Mater. 1, 7129-7138. doi: 10.1021/acsanm.8b02019

Coutanceau, C., Urchaga, P., Brimaud, S., and Baranton, S. (2012). Colloidal syntheses of shape- and size-controlled Pt nanoparticles for electrocatalysis. Electrocatalysis 3, 75-87. doi: 10.1007/s12678-012-0079-0

Crespo-Quesada, M., Andanson, J.-M., Yarulin, A., Lim, B., Xia, Y., and KiwiMinsker, L. (2011). UV-Ozone cleaning of supported poly(vinylpyrrolidone)stabilized palladium nanocubes: effect of stabilizer removal on morphology and catalytic behavior. Langmuir 27, 7909-7916. doi: 10.1021/la201007m

DeSimone, W. L., and Breen, J. J. (1995). Structures of iodine on Pt (110) single crystal electrode surfaces. Langmuir 11, 4428-4432. doi: 10.1021/la00011a040

Devivaraprasad, R., Kar, T., Chakraborty, A., Singh, R. K., and Neergat, M. (2016). Reconstruction and dissolution of shape-controlled Pt nanoparticles in acidic electrolytes, Phys. Chem. Chem. Phys. 18, 11220-11232. doi: 10.1039/C5CP07832F

Devivaraprasad, R., Kar, T., Leuaa, P., and Neergat, M. (2017). Recovery of active surface sites of shape-controlled platinum nanoparticles contaminated with halide ions and its effect on surface-structure. J. Electrochem. Soc. 164, H551-H560. doi: 10.1149/2.0171709jes

Devivaraprasad, R., Rahul, R., Naresh, N., Kar, T., Singh, R. K., and Neergat, M. (2014). Oxygen reduction reaction and peroxide generation on shapecontrolled and polycrystalline platinum nanoparticles in acidic and alkaline electrolytes. Langmuir 30, 8995-9006. doi: 10.1021/la501109g

Durst, J., Chatenet, M., and Maillard, F. (2012). Impact of metal cations on the electrocatalytic properties of $\mathrm{Pt} / \mathrm{C}$ nanoparticles at multiple phase interfaces. Phys. Chem. Chem. Phys. 14, 13000-13009. doi: 10.1039/C2CP42191G

Ehrenburg, M. R., Danilov, A. I., Botryakova, I. G., Molodkina, E. B., and Rudnev, A. V. (2017). Electroreduction of nitrate anions on cubic and polyoriented platinum nanoparticles modified by copper adatoms. J. Electroanal. Chem. 802, 109-117. doi: 10.1016/j.jelechem.2017.08.051

Erikson, H., Lusi, M., Sarapuu, A., Tammeveski, K., Solla-Gullón, J., and Feliu, J. M. (2016). Oxygen electroreduction on carbon-supported Pd nanocubes in acid solutions, Electrochim. Acta 188, 301-308. doi: 10.1016/j.electacta.2015.11.125

Erikson, H., Sarapuu, A., Alexeyeva, N., Tammeveski, K., Solla-Gullón, J., and Feliu, J. M. (2012). Electrochemical reduction of oxygen on palladium nanocubes in acid and alkaline solutions. Electrochim. Acta 59, 329-335. doi: 10.1016/j.electacta.2011.10.074

Erikson, H., Sarapuu, A., Tammeveski, K., Solla-Gullón, J., and Feliu, J. M. (2011). Enhanced electrocatalytic activity of cubic Pd nanoparticles towards the oxygen reduction reaction in acid media. Electrochem. Commun. 13, 734-737. doi: 10.1016/j.elecom.2011.04.024

Ernst, S., Aldous, L., and Compton, R. G. (2011). The electrochemical reduction of oxygen at boron-doped diamond and glassy carbon electrodes: a comparative study in a room-temperature ionic liquid. J. Electroanal. Chem. 663, 108-112. doi: 10.1016/j.jelechem.2011.10.004

Evans, R. G., Klymenko, O. V., Saddoughi, S. A., Hardacre, C., and Compton, R. G. (2004). Electroreduction of oxygen in a series of room temperature ionic liquids composed of group 15-centered cations and anions. J. Phys. Chem. B 108, 7878-7886. doi: 10.1021/jp031309i

Farias, M.J. S., Busó-Rogero, C., Vidal-Iglesias, F. J., Solla-Gullón, J., Camara, G. A., and Feliu, J. M. (2017). Mobility and oxidation of adsorbed co on shape-controlled Pt nanoparticles in acidic medium. Langmuir 33, 865-871. doi: 10.1021/acs.langmuir.6b03612

Farias, M. J. S., Vidal-Iglesias, F. J., Solla-Gullón, J., Herrero, E., and Feliu, J. M. (2014). On the behaviour of CO oxidation on shape-controlled
Pt nanoparticles in alkaline medium. J. Electroanal. Chem. 716, 16-22. doi: 10.1016/j.jelechem.2013.07.017

Feliu, J. M., Llorca, M. J., Gomez, R., and Aldaz, A. (1993). Electrochemical behaviour of irreversibly adsorbed tellurium dosed from solution on $\mathrm{Pt}(\mathrm{h}, \mathrm{k}, \mathrm{l})$ single crystal electrodes in sulphuric and perchloric acid media. Surf. Sci. 297, 209-222. doi: 10.1016/0039-6028(93)90265-L

Ferreira, P. J., O’La, G. J., Shao-Horn, Y., Morgan, D., Makharia, R., Kocha, S., et al. (2005). Instability of $\mathrm{Pt} / \mathrm{C}$ electrocatalysts in proton exchange membrane fuel cells a mechanistic investigation. J. Electrochem. Soc. 152, A2256-A2271. doi: 10.1149/1.2050347

Gao, X., Chen, X., Li, Z. H., and He, H. (2019). Direct synthesis of in-situ chirally modified palladium nanocrystals without capping agents and their application in heterogeneous enantioselective hydrogenations. ACS Catal. 9, 6100-6110. doi: 10.1021 /acscatal.9b00762

Garcia-Araez, N., Climent, V., Herrero, E., and Feliu, J. M. (2004). On the electrochemical behavior of the $\operatorname{Pt}\left(\begin{array}{lll}1 & 0 & 0\end{array}\right)$ vicinal surfaces in bromide solutions. Surf. Sci. 560, 269-284. doi: 10.1016/j.susc.2004.04.051

Garcia-Araez, N., Climent, V., Herrero, E., Feliu, J. M., and Lipkowski, J. (2005). Thermodynamic studies of chloride adsorption at the $\operatorname{Pt}\left(\begin{array}{lll}1 & 1 & 1\end{array}\right)$ electrode surface from $0.1 \mathrm{M} \mathrm{HClO} 4$ solution. J. Electroanal. Chem. 576, 33-41. doi: 10.1016/j.jelechem.2004.10.003

Garcia-Araez, N., Climent, V., Herrero, E., Feliu, J. M., and Lipkowski, J. (2006a). Thermodynamic studies of bromide adsorption at the Pt $\left(\begin{array}{lll}1 & 1 & 1\end{array}\right)$ electrode surface perchloric acid solutions: comparison with other anions. J. Electroanal. Chem. 591, 149-158. doi: 10.1016/j.jelechem.2006.04.008

Garcia-Araez, N., Lukkien, J. J., Koper, M. T. M., and Feliu, J. M. (2006b). Competitive adsorption of hydrogen and bromide on Pt $\left(\begin{array}{lll}1 & 0 & 0\end{array}\right)$ : mean-field approximation vs. Monte Carlo simulations. J. Electroanal. Chem. 588, 1-14. doi: 10.1016/j.jelechem.2005.11.034

García-Cruz, L., Montiel, V., and Solla-Gullón, J. (2019). Shape-controlled metal nanoparticles for electrocatalytic applications. Phys. Sci. Rev. doi: 10.1515/psr-2017-0124. [Epub ahead of print].

Gilroy, K. D., Yang, X., Xie, S., Zhao, M., Qin, D., and Xia, Y. (2018). Shape-controlled synthesis of colloidal metal nanocrystals by replicating the surface atomic structure on the seed. Adv. Mater. 30:1706312. doi: 10.1002/adma.201706312

Girishkumar, G., McCloskey, B., Luntz, A. C., Swanson, S., and Wilcke, W. (2010). Lithium-air battery: promise and challenges. J. Phys. Chem. Lett. 1, 2193-2203. doi: $10.1021 /$ jz1005384

Gomez, R., Llorca, M. J., Feliu, J. M., and Aldaz, A. (1992). The behaviour of germanium adatoms irreversibly adsorbed on platinum single crystals. $J$. Electroanal. Chem. 340, 349-355. doi: 10.1016/0022-0728(92)80310-Z

Gou, S., Zhang, S., and Sun, S. (2013). Tuning nanoparticle catalysis for the oxygen reduction reaction. Angew. Chem. Int. Ed. 52, 8526-8854. doi: 10.1002/anie.201207186

Grozovski, V., Solla-Gullón, J., Climent, V., Herrero, E., and Feliu, J. M. (2010). Formic acid oxidation on shape-controlled Pt nanoparticles studied by pulsed voltammetry. J. Phys. Chem. C 114, 13802-13812. doi: 10.1021/jp104755b

Gumeci, C., Marathe, A., Behrens, R. L., Chaudhuri, J., and Korzeniewski, C. (2014). Solvothermal synthesis and electrochemical characterization of shape-controlled Pt nanocrystals. J. Phys. Chem. C 118, 14433-14440. doi: $10.1021 /$ jp5037525

Guo, S., and Wang, E. (2011). Noble metal nanomaterials: controllable synthesis and application in fuel cells and analytical sensors. Nano Today 6, 240-264. doi: 10.1016/j.nantod.2011.04.007

Halseid, R., Heinen, M., Jusys, Z., and Behm, R. J. (2008). The effect of ammonium ions on oxygen reduction and hydrogen peroxide formation on polycrystalline Pt electrodes. J. Power Sources 176, 435-443. doi: 10.1016/j.jpowsour.2007.08.067

He, Q., Yang, X., Chen, W., Mukherjee, S., Koelb, B., and Chen, S. (2010). Influence of phosphate anion adsorption on the kinetics of oxygen electroreduction on low index Pt (hkl) single crystals. Phys. Chem. Chem. Phys. 12, 12544-12555. doi: 10.1039/C0CP00433B

Hoshi, N., Nakamura, M., Kida, K., Nakamura, M., Nakada, M., and Osada, K. (2006). Structural effects of electrochemical oxidation of formic acid on single crystal electrodes of palladium. J. Phys. Chem. B 110, 12480-12484. doi: $10.1021 /$ jp0608372 
Housmans, T. H. M., and Koper, M. T. M. (2003). Methanol oxidation on stepped $\mathrm{Pt}[\mathrm{n}(111) \times(110)]$ electrodes: a chronoamperometric study. J. Phys. Chem. B 107, 8557-8567. doi: 10.1021/jp034291k

Hsueh, K. L., Gonzalez, E. R., and Srinivasan, S. (1983). Electrolyte effects on oxygen reduction kinetics at platinum: a rotating ring-disc electrode analysis. Electrochim. Acta 28, 691-697. doi: 10.1016/0013-4686(83)85066-X

Huang, H., Wang, Y., Ruditskiy, A., Peng, H.-C., Zhao, X., Zhang, L., et al. (2014). Polyol syntheses of palladium decahedra and icosahedra as pure samples by maneuvering the reaction kinetics with additives. ACS Nano 8, 7041-7050. doi: $10.1021 / \mathrm{nn} 501919 \mathrm{e}$

Jin, M., Liu, H., Zhang, H., Xie, Z., Liu, J., and Xia, Y. (2011a). Synthesis of Pd nanocrystals enclosed by $\{100\}$ facets and with sizes $<10 \mathrm{~nm}$ for application in CO oxidation. Nano Res. 4, 83-91. doi: 10.1007/s12274-010-0051-3

Jin, M., Zhang, H., Xie, Z., and Xia, Y. (2011b). Palladium concave nanocubes with high-index facets and their enhanced catalytic properties. Angew. Chem. Inter. Ed. 50, 7850-7854. doi: 10.1002/anie.201103002

Jukk, K., Kongi, N., Tammeveski, K., Arán-Ais, R. M., Solla-Gullón, J., and Feliu, J. M. (2017). Loading effect of carbon-supported platinum nanocubes on oxygen electroreduction. Electrochim. Acta 251, 155-166. doi: 10.1016/j.electacta.2017.08.099

Kang, Y., Pyo, J. B., Ye, X., Diaz, R. E., Gordon, T. R., Stach, E. A., et al. (2013). Shape-controlled synthesis of Pt nanocrystals: the role of metal carbonyls. ACS Nano 7, 645-653. doi: 10.1021/nn3048439

Kinoshita, K., Lundquist, J. T., and Stonehart, P. (1973). Potential cycling effects on platinum electrocatalyst surfaces. J. Electroanal. Chem. Interfacial Electrochem. 48, 157-166. doi: 10.1016/S0022-0728(73)80257-8

Kolb, D. M. (1995). Reconstruction phenomena at metal-electrolyte interfaces. Prog. Surf. Sci. 51, 109-173. doi: 10.1016/0079-6816(96)00002-0

Komanicky, V., Chang, K. C., Menzel, A., Marković, N. M., You, H., Wang, X., et al. (2006). Stability and dissolution of platinum surfaces in perchloric acid. $J$. Electrochem. Soc. 153, B446-B451. doi: 10.1149/1.2229284

Kondo, S., Nakamura, M., Maki, N., and Hoshi, N. (2009). Active sites for the oxygen reduction reaction on the low and high index planes of palladium. J. Phys. Chem. C 113, 12625-12628. doi: 10.1021/jp904278b

Kongkanand, A., and Ziegelbauer, J. M. (2012). Surface platinum electrooxidation in the presence of oxygen. J. Phys. Chem. C 116, 3684-3693. doi: $10.1021 /$ jp211490a

Laoire, C. O., Mukerjee, S., Abraham, K. M., Plichta, E. J., and Hendrickson, M. A. (2010). Influence of nonaqueous solvents on the electrochemistry of oxygen in the rechargeable lithium-air battery. J.Phys. Chem. C 114, 9178-9186. doi: $10.1021 /$ jp102019y

Lee, C.-L., Chiou, H.-P., and Liu, C.-R. (2012a). Palladium nanocubes enclosed by (100) planes as electrocatalyst for alkaline oxygen electroreduction. Int. J. Hydrogn. Energy 37, 3993-3997. doi: 10.1016/j.ijhydene.2011.11.118

Lee, H. (2014). Utilization of shape-controlled nanoparticles as catalysts with enhanced activity and selectivity. RSC Adv. 4, 41017-41027. doi: 10.1039/C4RA05958A

Lee, H., Kim, C., Yang, S., Han, J. W., and Kim, J. (2012b). Shapecontrolled nanocrystals for catalytic applications. Catal. Surv. Asia 16, 14-27. doi: 10.1007/s10563-011-9130-z

Lee, Y.-W., Lee, J.-Y., Kwak, D.-H., Hwang, E.-T., Sohn, J. I., and Park, K.W. (2015). Pd@Pt core-shell nanostructures for improved electrocatalytic activity in methanol oxidation reaction. Appl. Catal. B Environ. 179, 178-184. doi: 10.1016/j.apcatb.2015.05.029

Li, H., Chen, G., Yang, H., Wang, X., Liang, J., Liu, P., et al. (2013). Shape-controlled synthesis of surface-clean ultrathin palladium nanosheets by simply mixing a dinuclear PdI carbonyl chloride complex with $\mathrm{H}_{2} \mathrm{O}$. Angew. Chem. Inter. Ed. 52, 8368-8372. doi: 10.1002/anie.201303772

Liu, S.-Y., Shen, Y.-T., Chiu, C.-Y., Rej, S., Lin, P.-H., Tsao, Y.-C., et al. (2015). Direct synthesis of palladium nanocrystals in aqueous solution with systematic shape evolution. Langmuir 31, 6538-6545. doi: 10.1021/acs.langmuir.5b01337

Liu, X., Li, W., and Zou, S. (2017). Electrocatalysis of Facet-controlled Noble Metal Nanomaterials for Low-temperature Fuel Cells. Oxford: Wiley-VCH Verlag $\mathrm{GmbH} \& \mathrm{Co} . \mathrm{KGaA}$.

Long, N. V., Ohtaki, M., Nogami, M., and Hien, T. D. (2011). Effects of heat treatment and poly(vinylpyrrolidone) (PVP) polymer on electrocatalytic activity of polyhedral Pt nanoparticles towards their methanol oxidation. Colloid Polym. Sci. 289, 1373-1386. doi: 10.1007/s00396-011-2460-6
Lopes, P. P., Strmcnik, D., Tripkovic, D., Connell, J. G., Stamenkovic, V. R., and Markovic, N. M. (2016). Relationships between atomic level surface structure and stability/activity of platinum surface atoms in aqueous environments. ACS Catal. 6, 2536-2544. doi: 10.1021/acscatal.5b02920

Lu, Y., Wang, J., Peng, Y., Fisher, A., and Wang, X. (2017). Highly efficient and durable Pd hydride nanocubes embedded in $2 \mathrm{D}$ amorphous $\mathrm{NiB}$ nanosheets for oxygen reduction reaction. Adv. Energy Mater. 7, 1700919-1700926. doi: 10.1002/aenm.201700919

Lu, Y.-C., Gasteiger, H. A., and Shao-Horn, Y. (2011). Catalytic activity trends of oxygen reduction reaction for nonaqueous li-air batteries. J. Am. Chem. Soc. 133, 19048-19051. doi: 10.1021/ja208608s

Macia, M. D., Campina, J. M., Herrero, E., and Feliu, J. M. (2004). On the kinetics of oxygen reduction on platinum stepped surfaces in acidic media. J. Electroanal. Chem. 564, 141-150. doi: 10.1016/j.jelechem.2003.09.035

Marković, N. M., Adzic, R. R., Cahan, B. D., and Yeager, E. B. (1994). Structural effects in electrocatalysis: oxygen reduction on platinum low index single-crystal surfaces in perchloric acid solutions. $J$. Electroanal. Chem. 377, 249-259. doi: 10.1016/0022-0728(94)0 $3467-2$

Marković, N. M., Gasteiger, H. A, Grgur, B. N., and Ross, P. N. (1999). Oxygen reduction reaction on Pt (111): effects of bromide. J. Electroanal. Chem. 467, 157-163. doi: 10.1016/S0022-0728(99)0 0020-0

Marković, N. M., Gasteiger, H. A., and Ross, P. N. (1995). Oxygen reduction on platinum low-index single-crystal surfaces in sulfuric acid solution: rotating ring-Pt(hkl) disk studies. J. Phys. Chem. 99, 3411-3415. doi: 10.1021/j100011a001

Marković, N. M., Gasteiger, H. A., and Ross, P. N. (1997). Kinetics of oxygen reduction on $\mathrm{Pt}(\mathrm{hkl})$ electrodes: implications for the crystallite size effect with supported Pt electrocatalysts. J. Electrochem. Soc. 144, 1591-1597. doi: $10.1149 / 1.1837646$

Marković, N. M., Marinkovic, N. S., and Adzic, R. R. (1988). Electrosorption of hydrogen and sulphuric acid anions on single-crystal platinum stepped surfaces: part I. The [110] zone. J. Electroanal. Chem. 241, 309-328. doi: 10.1016/0022-0728(88)85134-9

Marković, N. M., Marinkovic, N. S., and Adzic, R. R. (1991). Electrosorption of hydrogen and sulfuric acid anions on single crystal platinum stepped surfaces. II. The $[110]$ zone. J. Electroanal. Chem. 314, 289-306. doi: 10.1016/0022-0728(91)85443-S

Martinez-Rodriguez, R. A., Vidal-Iglesias, F. J., Solla-Gullón, J., Cabrera, C. R., and Feliu, J. M. (2014). Synthesis of Pt nanoparticles in water-in-oil microemulsion: effect of $\mathrm{HCl}$ on their surface structure. J. Am. Chem. Soc. 136, 1280-1283. doi: $10.1021 /$ ja $411939 \mathrm{~d}$

Matsumoto, M., Miyazaki, T., and Imai, H. (2011). Oxygen-enhanced dissolution of platinum in acidic electrochemical environments. J. Phys. Chem. C 115, 11163-11169. doi: 10.1021/jp201959h

Mayet N., Servat K., Kokoh K. B., and Napporn T. W. (2019). Probing the surface of noble metals electrochemically by underpotential deposition of transition metals. Surfaces 2, 257-276. doi: 10.3390/surfaces 2020020

Mazumder, V., and Sun, S. (2009). Oleylamine-mediated synthesis of Pd nanoparticles for catalytic formic acid oxidation. J. Am. Chem. Soc. 131, 4588-4589. doi: 10.1021/ja9004915

Meier, J., Kleine, H., and Stimming, U. (2005). Investigations of the stability of palladium clusters supported on gold. Surf. Sci. 597, 127-132 doi: 10.1016/j.susc.2004.07.058

Mittermeier, A., Weiß, A., Hasché, F., and Gasteiger, H. A. (2015). Activity, stability, and degradation of carbon supported palladium $(\mathrm{Pd} / \mathrm{c})$ fuel cell electrocatalysts for the oxygen reduction. ECS Trans. 69, 303-313. doi: 10.1149/06917.0303ecs

Mittermeier, T., Weiß, A., Gasteiger, H. A., and Hasché, F. (2017). Monometallic palladium for oxygen reduction in PEM fuel cells: particle-size effect, reaction mechanism, and voltage cycling stability. J. Electrochem. Soc. 164, F1081F1089. doi: $10.1149 / 2.0561712$ jes

Monzo, J., Koper, M. T. M., and Rodriguez, P. (2012). Removing polyvinylpyrrolidone from catalytic Pt nanoparticles without modification of superficial order. Chem. Phys. Chem. 13, 709-715. doi: 10.1002/cphc.201100894

Mourdikoudis, S., and Liz-Marzán, L. M. (2013). Oleylamine in nanoparticle synthesis. Chem.Mater. 25, 1465-1476. doi: 10.1021/cm4000476 
Naito, K., Nakamura, M., Sakata, O., and Hoshi, N. (2011). Surface X-ray scattering of $\mathrm{Pd}(111)$ and $\mathrm{Pd}(100)$ electrodes during the oxygen reduction reaction. Electrochemistry 79, 256-260. doi: 10.5796/electrochemistry.79.256

Nalajala, N., Chakraborty, A., Bera, B., and Neergat, M. (2016). Chloride $\left(\mathrm{Cl}^{-}\right)$ ion-mediated shape-control of palladium nanoparticles. Nanotechnology 27, 065603-065615. doi: 10.1088/0957-4484/27/6/065603

Nalajala, N., Wasim, F. G. S., Ladewig, B. P., and Neergat, M. (2014). Sodium borohydride treatment: a simple and effective process for the removal of stabilizer and capping agents from shape-controlled palladium nanoparticles, Chem. Commun. 50, 9365-9368. doi: 10.1039/C4CC02747G

Nalajala, N., Wasim, F. G. S., Ladewig, B. P., and Neergat,. M. (2013). Removal of surfactant and capping agent from Pd nanocubes (Pd-NCs) using tertbutylamine: its effect on electrochemical characteristics. J. Mater. Chem. A 1, 8553-8559. doi: 10.1039/C3TA11183K

Naskar, S., Freytag, A., Deutsch, J., Wendt, N., Behrens, P., Köckritz, A., et al. (2017). Porous aerogels from shape-controlled metal nanoparticles directly from non-polar colloidal solution. Chem. Mater. 29, 9208-9217. doi: $10.1021 /$ acs.chemmater.7b03088

Niu, W., Zhang, L., and Xu, G. (2010). Shape-controlled synthesis of single-crystalline palladium nanocrystals. ACS Nano 4, 1987-1996. doi: $10.1021 / \mathrm{nn} 100093 \mathrm{y}$

Niu, W., Zhang, W., Firdoz, S., and Lu, X. (2014). Controlled synthesis of palladium concave nanocubes with sub-10-nanometer edges and corners for tunable plasmonic property. Chem. Mater. 26, 2180-2186. doi: $10.1021 / \mathrm{cm} 500210 \mathrm{u}$

Niu, Z., and Li., Y. (2014). Removal and utilization of capping agents in nanocatalysis. Chem. Mater. 26, 72-83. doi: 10.1021/cm4022479

Niu, Z., Peng, Q., Gong, M., Rong, H., and Li, Y. (2011). Oleylamine-mediated shape evolution of palladium nanocrystals. Angew. Chem. Inter. Ed. 50, 6315-6319. doi: 10.1002/anie.201100512

Nørskov, J. K., Rossmeisl, J., Logadottir, A., Lindqvist, L., Kitchin, J. R., Bligaard, T., et al. (2004). Origin of the overpotential for oxygen reduction at a fuel-cell cathode. J. Phys. Chem. B 108, 17886-17892. doi: 10.1021/jp0 $47349 \mathrm{j}$

Oelgeklaus, R., Rose, J., and Baltruschat, H. (1994). On the rate of hydrogen and iodine adsorption on polycrystalline Pt and Pt (111). J. Electroanal. Chem. 376, 127-133. doi: 10.1016/0022-0728(94)03439-7

Okada, T., Dale, J., Ayato, Y., Asbjørnsen, O. A., Yuasa, M., and Sekine, I. (1999). Unprecedented effect of impurity cations on the oxygen reduction kinetics at platinum electrodes covered with perfluorinated ionomer. Langmuir 15, 8490-8496. doi: 10.1021/la990625e

Ong, A. L., Whelligan, D. K., Fox, M. L., and Varcoe, J. R. (2013). Impact of $1 \mathrm{mmol} \mathrm{dm}^{-3}$ concentrations of small molecules containing nitrogen-based cationic groups on the oxygen reduction reaction on polycrystalline platinum in aqueous KOH $\left(1 \mathrm{~mol} \mathrm{dm}^{-3}\right)$. Phys. Chem. Chem. Phys. 15, 18992-19000. doi: $10.1039 / \mathrm{C} 3 \mathrm{CP} 50556 \mathrm{~A}$

Peng, H.-C., Li, Z., Aldahondo, G., Huang, H., and Xia, Y. (2016). Seedmediated synthesis of Pd nanocrystals: the effect of surface capping on the heterogeneous nucleation and growth. J. Phys. Chem. C 120, 11754-11761. doi: 10.1021 acs.jpcc.6b04679

Peng, Z., and Yang, H. (2009). Designer platinum nanoparticles: control of shape, composition in alloy, nanostructure and electrocatalytic property. Nano Today 4, 143-164. doi: 10.1016/j.nantod.2008.10.010

Perales-Rondón, J. V., Solla-Gullón, J., Herrero, E., and Sánchez-Sánchez, C. M. (2017). Enhanced catalytic activity and stability for the electrooxidation of formic acid on lead modified shape controlled platinum nanoparticles. Appl. Catal. B Environ. 201, 48-57. doi: 10.1016/j.apcatb.2016.08.011

Pronkin, S. N., Simonov, P. A., Zaikovskii, V. I., and Savinova, E. R. (2007). Model Pd-based bimetallic supported catalysts for nitrate electroreduction. J. Mol. Catal. A Chem. 265, 141-147. doi: 10.1016/j.molcata.2006.10.007

Quan, Z. W., Wang, Y. X., and Fang, J. Y. (2013). High-index faceted noble metal nanocrystals. Acc. Chem. Res. 46, 191-202. doi: 10.1021/ar200293n

Rahul, R., Singh, R. K., Bera, B., Devivaraprasad, R., and Neergat, M. (2015). The role of surface oxygenated-species and adsorbed hydrogen in the oxygen reduction reaction (ORR) mechanism and product selectivity on Pdbased catalysts in acid media. Phys. Chem. Chem. Phys. 17, 15146-15155. doi: $10.1039 /$ C5CP00692A
Rizo, R., Herrero, E., and Feliu, J. M. (2013). Oxygen reduction reaction on stepped platinum surfaces in alkaline media. Phys. Chem. Chem. Phys. 15, 15416-15425. doi: 10.1039/C3CP51642C

Rodes, A., El Achi, K., Zamakhchari, M. A., and Clavilier, J. (1990). Hydrogen probing of step and terrace sites on $\mathrm{Pt}(\mathrm{S})-[n(111) \times(100)]$. J. Electroanal. Chem. 284, 245-253. doi: 10.1016/0022-0728(90)87077-W

Rodriguez, P., Herrero, E., Solla-Gullón, J., Vidal-Iglesias, F. J., Aldaz, A., and Feliu, J. M. (2005). Electrochemical Characterization of Irreversibly Adsorbed Germanium on Platinum Stepped Surfaces Vicinal to $\operatorname{Pt}\left(\begin{array}{lll}1 & 0 & 0\end{array}\right)$. Electrochim. Acta 50, 3111-3121. doi: 10.1016/j.electacta.2004.10.086

Ruan, L., Chiu, C.-Y., Li, Y., and Huang, Y. (2011). Synthesis of platinum singletwinned right bipyramid and $\{111\}$-bipyramid through targeted control over both nucleation and growth using specific peptides. Nano Lett. 11, 3040-3046. doi: $10.1021 / \mathrm{nl} 201958 \mathrm{w}$

Ruditskiy, A., Vara, M., Huang, H., and Xia, Y. (2017). Oxidative etching of Pd decahedral nanocrystals with a penta-twinned structure and its impact on their growth behavior. Chem. Mater. 29, 5394-5400. doi: $10.1021 /$ acs.chemmater.7b01776

Safo, I. A., and Oezaslan, M. (2017). Electrochemical cleaning of polyvinylpyrrolidone-capped Pt nanocubes for the oxygen reduction reaction. Electrochim. Acta 241, 544-552. doi: 10.1016/j.electacta.2017.04.118

Salaita, G. N., Stern, D. A., Lu, F., Baltruschat, H., Schardt, B. C., Stickney, J. L., et al. (1986). Structure and composition of a platinum (111) surface as a function of $\mathrm{pH}$ and electrode potential in aqueous bromide solutions. Langmuir 2, 828-835. doi: 10.1021/la00072a031

Sanchez-Sanchez, C. M., Solla-Gullón, J., Vidal-Iglesias, F. J., Aldaz, A., Montiel, V., and Herrero, E. (2010). Imaging structure sensitive catalysis on different shape-controlled platinum nanoparticles. J. Am. Chem. Soc. 132, 5622-5624. doi: $10.1021 /$ ja100922h

Schmidt, T. J., Paulus, U. A., Gasteiger, H. A., and Behm, R. J. (2001). The oxygen reduction reaction on a $\mathrm{Pt} /$ carbon fuel cell catalyst in the presence of chloride anions. J. Electroanal. Chem. 508, 41-47. doi: 10.1016/S0022-0728(01)00499-5

Schwenke, K. U., Herranz, J., Gasteiger, H. A., and Piana, M. (2015). Reactivity of the ionic liquid Pyr14TFSI with superoxide radicals generated from $\mathrm{KO}_{2}$ or by contact of $\mathrm{O}_{2}$ with $\mathrm{Li}_{7} \mathrm{Ti}_{5} \mathrm{O}_{12}$. J. Electrochem. Soc. 162, A905-A914. doi: $10.1149 / 2.0241506$ jes

Shao, M. (2011). Palladium-based electrocatalysts for hydrogen oxidation and oxygen reduction reactions. J. Power Sources 196, 2433-2444. doi: 10.1016/j.jpowsour.2010.10.093

Shao, M., Odell, J., Humbert, M., Yu, T., and Xia, Y. (2013). Electrocatalysis on shape-controlled palladium nanocrystals: oxygen reduction reaction and formic acid oxidation. J. Phys. Chem. C 117, 4172-4180. doi: 10.1021/jp312859x

Shao, M., Yu, T., Odell, J. H., Jin, M., and Xia, Y. (2011). Structural dependence of oxygen reduction reaction on palladium nanocrystals. Chem. Commun. 47, 6566-6568. doi: 10.1039/C1CC11004G

Shao-Horn, Y., Sheng, W. C., Chen, S. P., Ferreira, J., Holby, E. F., and Morgan, D. (2007). Instability of supported platinum nanoparticles in low-temperature fuel cells. Top. Catal. 46, 285-305. doi: 10.1007/s11244-007-9000-0

Shu, Z. X., and Bruckenstein, S. (1991). Iodine adsorption studies at platinum. J. Electroanal. Chem. 317, 263-277. doi: 10.1016/0022-0728(91)85019-L

Singh, R. K., Rahul, R., and Neergat, M. (2013). Stability issues in Pd-based catalysts: the role of surface $\mathrm{Pt}$ in improving the stability and oxygen reduction reaction (ORR) activity. Phys. Chem. Chem. Phys. 15, 13044-13051. doi: 10.1039/C3CP50697E

Sneed, B. T., Kuo, C.-H., Brodsky, C. N., and Tsung, C.-K. (2012). Iodide-mediated control of rhodium epitaxial growth on well- defined noble metal nanocrystals: synthesis, characterization, and structure-dependent catalytic properties. J. Am. Chem. Soc. 134, 18417-18426. doi: 10.1021/ja308030h

Solla-Gullón J., Vidal-Iglesias F. J., Rodríguez P., Herrero E., Feliu, J. M., Clavilier, J., et al. (2004). In situ surface characterization of preferentially oriented platinum nanoparticles by using electrochemical structure sensitive adsorption reactions. J. Phys. Chem. B 108, 13573-13575. doi: 10.1021/jp0471453

Solla-Gullón, J., Montiel, V., Aldaz, A., and Clavilier, J. (2003). Synthesis and electrochemical decontamination of platinum-palladium nanoparticles prepared by water-in-oil microemulsion. Electrochem. Soc. 150, E104-E109. doi: $10.1149 / 1.1534600$ 
Solla-Gullón, J., Rodriguez, P., Herrero, E., Aldaz, A., and Feliu, J. M. (2008). Surface characterization of platinum electrodes. Phys. Chem. Chem. Phys. 10, 1359-1373. doi: 10.1039/B7 09809J

Solomun, T., Wieckowski, A., Rosasco, S. D., and Hubbard, A. T. (1984). Iodine adsorption on a platinum stepped surface: $\mathrm{Pt}(\mathrm{s})[6(111) \times(111)]$. Surf. Sci. 147, 241-251. doi: 10.1016/0039-6028(84)90178-X

Sreedhala, S., Sudheeshkumar, V., and Vinod, C. P. (2014). Structure sensitive chemical reactivity by palladium concave nanocubes and nanoflowers synthesised by a seed mediated procedure in aqueous medium. Nanoscale 6 , 7496-7502. doi: 10.1039/C4NR01283F

Stamenkovic, V., Grgur, B. N., Ross, P. N., and Marković, N. M. (2005). Oxygen reduction reaction on Pt and Pt-bimetallic electrodes covered by CO mechanism of the air bleed effect with reformate. J. Electrochem. Soc. 152, A277-A282. doi: 10.1149/1.1845321

Stamenkovic, V., Marković, N. M., and Ross, P. N. Jr. (2001). Structurerelationships in electrocatalysis: oxygen reduction and hydrogen oxidation reactions on $\mathrm{Pt}$ (111) and $\mathrm{Pt}$ (100) in solutions containing chloride ions. J. Electroanal. Chem. 500, 44-51. doi: 10.1016/S0022-0728(00)0 0352-1

Stamenkovic, V., Mun, B. S., Mayrhofer, K. J. J., and Ross, P. N. (2006). Effect of surface composition on electronic structure, stability, and electrocatalytic properties of Pt-transition metal alloys: Pt-skin versus Pt-skeleton surfaces. J. Am. Chem. Soc. 128, 8813-8819. doi: 10.1021/ja 0600476

Stamenkovic, V., Schmidt, T. J., Ross, P. N., and Marković, N. M. (2002). Surface composition effects in electrocatalysis: kinetics of oxygen reduction on welldefined $\mathrm{Pt}_{3} \mathrm{Ni}$ and $\mathrm{Pt}_{3}$ Co alloy surfaces. J. Phys. Chem. B 106, 11970-11979. doi: $10.1021 /$ jp021182h

Sugawara, Y., Okayasu, T., Yadav, A. P., Nishikata, A., and Tsuru, T. (2012). Dissolution mechanism of platinum in sulfuric acid solution. J. Electroanal. Chem. 159, F779-F786. doi: 10.1149/2.017212jes

Sugawara, Y., Yadav, A. P., Nishikata, A., and Tsuru, T. (2011). Dissolution and surface area loss of platinum nanoparticles under potential cycling $J$. Electroanal. Chem. 662, 379-383. doi: 10.1016/j.jelechem.2011.09.009

Tang, L., Han, B., Persson, K., Friesen, C., He, T., Sieradzki, K., et al. (2010a). Electrochemical stability of nanometer-scale Pt particles in acidic environments. J. Am. Chem. Soc. 132, 596-600. doi: 10.1021/ja9071496

Tang, L., Li, X., Cammarata, R. C., Friesen, C., and Sieradzki, K. (2010b). Electrochemical stability of elemental metal nanoparticles. J. Am. Chem. Soc. 132, 11722-11726. doi: 10.1021/ja104421t

Tang, Y., Chi, X., Zou, S., and Zeng, X. (2016). Facet effects of palladium nanocrystals for oxygen reduction in ionic liquids and for sensing applications. Nanoscale 8, 5771-5779. doi: 10.1039/C5NR07502E

Tao, A. R., Habas, S., and Yang, P. D. (2008). Shape control of colloidal metal nanocrystals. Small 4, 310-325. doi: 10.1002/smll.200701295

Tian, N., Zhou, Z.-Y., Yu, N.-F., Wang, L.-Y., and Sun, S.-G. (2010). Direct electrodeposition of tetrahexahedral Pd nanocrystals with high-index facets and high catalytic activity for ethanol electrooxidation. J. Am. Chem. Soc. 132, 7580-7581. doi: $10.1021 / \mathrm{ja} 102177 \mathrm{r}$

Topalov, A. A., Cherevko, S., Zeradjanin, A. R., Meier, J. C., Katsounaros, I., and Mayrhofer, K. J. J. (2014a). Towards a comprehensive understanding of platinum dissolution in acidic media. J. Chem. Sci. 5, 631-638. doi: 10.1039/C3SC52411F

Topalov, A. A., Katsounaros, I., Auinger, M., Cherevko, S., Meier, J. C., Klemm, S. O., et al. (2012). Dissolution of platinum: limits for the deployment of electrochemical energy conversion? Angew. Chem. Int. Ed. 51, 12613-12615. doi: $10.1002 /$ anie. 201207256

Topalov, A. A., Zeradjanin, A. R., Cherevko, S., and Mayrhofer, K. J. J. (2014b). The impact of dissolved reactive gases on platinum dissolution in acidic media. Electrochem. Commun. 40, 49-53.

Tripkovic, D. V., Strmcnik, D., Van der Vliet, D., Stamenkovic, V., and Marković, N. M. (2008). The role of anions in surface electrochemistry. Faraday Discuss. 140, 25-40. doi: 10.1039/B803714K

Unnikrishnan, A., Janardhanan, V. M., Rajalakshmi, N., and Dhathathreyan, K. S. (2018). Chlorine-contaminated anode and cathode PEMFCrecovery perspective. J Solid State Electrochem. 22, 2107-2113. doi: $10.1007 /$ s10008-018-3921-3
Vara, M., Lu, P., Yang, X., Lee, C.-T., and Xia, Y. (2017). A photochemical, roomtemperature, and aqueous route to the synthesis of pd nanocubes enriched with atomic steps and terraces on the side faces. Chem. Mater. 29, 4563-4571. doi: 10.1021/acs.chemmater.7b01287

Vara, M., and Xia, Y. (2018). Facile synthesis of Pd concave nanocubes: from kinetics to mechanistic understanding and rationally designed protocol. Nano Res. 11, 3122-3131. doi: 10.1007/s12274-018-1967-2

Vidal-Iglesias, F. J., Arán-Ais, R. M., Solla-Gullón, J., Herrero, E., and Feliu, J. M. (2012). Electrochemical characterization of shape-controlled Pt nanoparticles in different supporting electrolytes. ACS Catal. 2, 901-910. doi: $10.1021 / \mathrm{cs} 200681 \mathrm{x}$

Vidal-Iglesias, F. J., Solla-Gullón, J., Herrero, E., Montiel, V., Aldaz, A., and Feliu, J. M. (2011). Evaluating the ozone cleaning treatment in shape-controlled Pt nanoparticles: evidences of atomic surface disordering. Electrochem. Commun. 13, 502-505. doi: 10.1016/j.elecom.2011.02.033

Vig, J. R. (1985). UV/ozone cleaning of surfaces. J. Vac. Sci. Technol. A 3 , 1027-1034. doi: $10.1116 / 1.573115$

Vogel, R., and Baltruschat, H. (1991). Iodine adlattice on Pt(100) observed by STM. Surf. Sci. Lett. 259, L739-L742. doi: 10.1016/0167-2584(91)90302-8

Wagner, F. T., and Ross, P. N. Jr. (1988). Long-range structural effects in the anomalous voltammetry on ultra-high vacuum prepared Pt (111). J. Electroanal. Chem. 250, 301-320. doi: 10.1016/0022-0728(88)85172-6

Wang, L., Zeng, Z., Gao, W., Maxson, T., Raciti, D., Giroux, M., et al. (2019). Tunable intrinsic strain in two-dimensional transition metal electrocatalysts. Science 363, 870-874. doi: 10.1126/science.aat8051

Wang, X., Kumar, R., and Myers, D. (2006). Effect of voltage on platinum dissolution relevance to polymer electrolyte fuel cells. J. Electrochem. Solid-State Lett. 9, A225-A227. doi: 10.1149/1.2180536

Wang, Y., Li, Z., Xu, S., Lei, F., and Lin, S. (2016). One pot synthesis of Pt/graphene composite using polyamidoamine/chitosan as a template and its electrocatalysis for methanol oxidation. Catalysts 6, 165-177. doi: 10.3390/catal6100165

Wang, Y., Xie, S., Liu, J., Park, J., Huang, C. Z., and Xia, Y. (2013). Shapecontrolled synthesis of palladium nanocrystals: a mechanistic understanding of the evolution from octahedrons to tetrahedrons. Nano Lett. 13, 2276-2281. doi: $10.1021 / \mathrm{nl} 400893 \mathrm{p}$

Wang, Z.-L., Xu, D., Xu, J.-J., and Zhang, X.-B. (2014). Oxygen electrocatalysts in metal-air batteries: from aqueous to nonaqueous electrolytes. Chem. Soc. Rev. 43, 7746-7786. doi: 10.1039/C3CS60248F

Watt, J., Young, N., Haigh, S., Kirkland, A., and Tilley, R. D. (2009). Synthesis and structural characterization of branched palladium nanostructures. Adv. Mater. 21, 2288-2293. doi: 10.1002/adma.200900272

Weiner, R. G., Kunz, M. R., and Skrabalak, S. E. (2015). Seeding a new kind of garden: synthesis of architecturally defined multimetallic nanostructures by seed-mediated co-reduction. Acc. Chem. Res. 48, 2688-2695. doi: $10.1021 /$ acs.accounts.5b00300

Wells, P. P., Crabb, E. M., King, C. R., Wiltshire, R., Billsborrow, B., Thompsett, D., et al. (2009). Preparation, structure, and stability of Pt and Pd monolayer modified Pd and Pt electrocatalysts. Phys. Chem. Chem. Phys. 11, 5773-5781. doi: $10.1039 / \mathrm{B} 823504 \mathrm{~J}$

Xia, Y., Gilroy, K. D., Peng, H.-C., and Xia, X. (2017). Seed-mediated growth of colloidal metal nanocrystals. Angew. Chem. Inter. Ed. 56, 60-95. doi: $10.1002 /$ anie.201604731

Xia, Y., Xia, X., and Peng, H.-C. (2015). Shape-controlled synthesis of colloidal metal nanocrystals: thermodynamic versus kinetic products. J. Am. Chem. Soc. 137, 7947-7966. doi: 10.1021/jacs.5b04641

Xia, Y. N., Xiong, Y. J., Lim,. B., and Skrabalak, S. E. (2009). Shape-controlled synthesis of metal nanocrystals: simple chemistry meets complex physics? Angew. Chem. Int. Ed. 48, 60-103. doi: 10.1002/anie.200802248

Xiao, L., Zhuang, L., Liu, Y., Lu,. J., and Abrun, H. D. (2009). Activating Pd by morphology tailoring for oxygen reduction. J. Am. Chem. Soc. 131, 602-608. doi: $10.1021 /$ ja 8063765

Xie, X., Gao, G., Pan, Z., Wang, T., Meng, X., and Cai, L. (2015). Large-scale synthesis of palladium concave nanocubes with high-index facets for sustainable enhanced catalytic performance. Sci. Rep. 5:8515. doi: $10.1038 /$ srep 08515

Xing, L., Hossain, M. A., Tian, M., Beauchemin, D., Adjemian, K. T., and Jerkiewicz, G. (2013). Platinum electro-dissolution in acidic media upon potential cycling. Electrocatalysis 5, 96-112. doi: 10.1007/s12678-013-0167-9 
Xu, D., Liu, X., Han, M., and Bao, J. (2016). Facile synthesis of ultrathin singlecrystalline palladium nanowires with enhanced electrocatalytic activities. Chem. Comm. 52, 12996-12999. doi: 10.1039/C6CC06711E

Yamamoto, K., Kolb, D. M., Kotz, R., and Lehmpfuhl, G. (1979). Hydrogen adsorption and oxide formation on platinum single crystal electrodes. J. Electroanal. Chem. 96, 233-239. doi: 10.1016/S0022-0728(79)80380-0

Yang, H., Tang, Y., and Zou, S. (2014). Electrochemical removal of surfactants from Pt nanocubes. Electrochem. Commun. 38, 134-137. doi: 10.1016/j.elecom.2013.11.019

Yang, L., Cheng, G., Guo, Y., Li, D., Xia, L., and Liu, H. (2018). Steam treatment: a facile and effective process for the removal of PVP from shape-controlled palladium nanoparticles. Nanoscale 10, 11992-11996. doi: 10.1039/C8NR02996B

Yasuda, K., Taniguchi, A., Akita, T., Ioroi, T., and Siroma, Z. (2006). Platinum dissolution and deposition in the polymerelectrolyte membrane of a PEM fuel cell as studied by potential cycling. Phys. Chem. Chem. Phys. 8, 746-752. doi: 10.1039/B514342J

Zadick, A., Dubau, L., Demirci, U. B., and Chatenet, M. (2016). Effects of Pd nanoparticle size and solution reducer strength on $\mathrm{Pd} / \mathrm{c}$ electrocatalyst stability in alkaline electrolyte. J. Electrochem. Soc. 63, F781-F787. doi: $10.1149 / 2.0141608$ jes

Zhang, H., Jin, M., Xiong, Y., Lim, B., and Xia, Y. (2013). Shape-controlled synthesis of pd nanocrystals and their catalytic applications. Acc. Chem. Res. 46, 1783-1794. doi: 10.1021/ar300209w

Zhang, H.-X., Wang, H., Re, Y.-S., and Cai, W.-B. (2012). Palladium nanocrystals bound by $\{110\}$ or $\{100\}$ facets:from one pot synthesis to electrochemistry. Chem. Comm. 48, 8362-8364. doi: 10.1039/C2CC 33941B

Zhang, J., Feng, C., Deng, Y., Liu, L., Wu, Y., Shen, B., et al. (2014). Shapecontrolled synthesis of palladium single-crystalline nanoparticles: the effect of $\mathrm{HCl}$ oxidative etching and facet-dependent catalytic properties. Chem. Mater. 26, 1213-1218. doi: 10.1021/cm403591g

Zhang, J., Zhang, L., Xie, S., Kuang, Q., Han, X., Xie, Z., et al. (2011). Synthesis of concave palladium nanocubes with high-index surfaces and high electrocatalytic activities. Chem. Euro. J. 17, 9915-9919. doi: 10.1002/chem.201100868

Zhang, X., Xia, Z., Huang, Y., Jia, Y., Sun, X., Li, X., et al. (2016). Shape-controlled synthesis of Pt nanopeanuts. Sci. Rep. 6, 31404-31410. doi: 10.1038/srep31404

Zhou, K. B., and Li, Y. D. (2012). Catalysis based on nanocrystals with well-defined facets. Angew. Chem. Int. Ed. 51, 602-613. doi: 10.1002/anie.201102619

Conflict of Interest: The authors declare that the research was conducted in the absence of any commercial or financial relationships that could be construed as a potential conflict of interest.

Copyright (c) 2019 Devivaraprasad, Nalajala, Bera and Neergat. This is an openaccess article distributed under the terms of the Creative Commons Attribution License (CC BY). The use, distribution or reproduction in other forums is permitted, provided the original author(s) and the copyright owner(s) are credited and that the original publication in this journal is cited, in accordance with accepted academic practice. No use, distribution or reproduction is permitted which does not comply with these terms. 